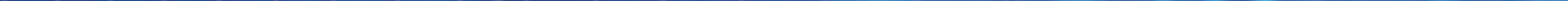




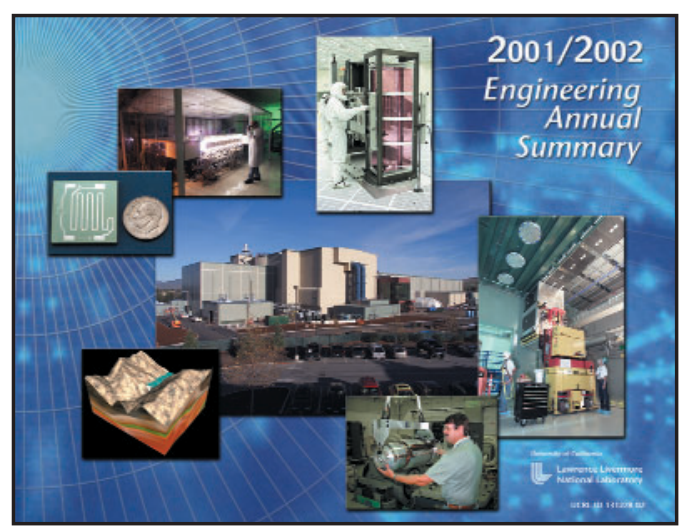

\section{About the cover:}

Engineering plays a vital role in achieving milestones for programs and projects throughout the Laboratory. For the National Ignition Facility, or NIF (pictured at center), engineers developed advanced optics fabrication techniques, completed significant portions of the beampath infrastructure, and installed and commissioned control room hardware and software. Several stockpile stewardship projects recorded important advances, as did efforts in computer modeling, biohazard detection for homeland security, and microtechnology. Engineering personnel played key roles in all of these accomplishments.

\section{Editor}

Don McNichols

Graphic Designer

Kathy McCullough

$$
\begin{aligned}
& \text { Art Team } \\
& \text { Lucy Dobson } \\
& \text { Debbie Marsh } \\
& \text { Irene Chan } \\
& \text { Jeff Bonivert }
\end{aligned}
$$

This report has been reproduced directly from the best available copy.

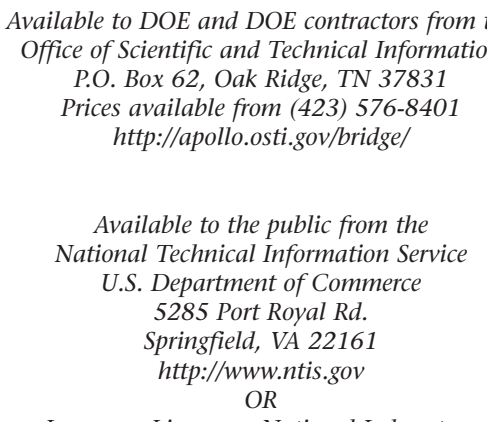

Lawrence Livermore National Laboratory

Innovative Buisiness and Information Services' Digital Library http://www.llnl.gov/library/index.html

This document was prepared as an account of work by an agency of the United States Government. Neither the United States Government nor the University of California nor any of their employees makes any warranty, express or implied, or assumes any legal liability or responsibility for the accuracy, completeness, or usefulness of any information, apparatus, product, or process disclosed, or represents that its use would not infringe privately owned rights. Reference herein to any specific commercial product, process, or service by trade name, trademark, manufacturer, or otherwise, does not necessarily constitute or imply its endorsement, recommendation, or favoring by the United States Government or the University of California. The views and opinions of authors expressed herein do not necessarily state or reflect those of the United States Government or the University of California, and shall not be used for advertising or product endorsement purposes.

Work performed under the auspices of the U.S. Department of Energy by the University of California Lawrence Livermore National Laboratory under Contract W-7405-Eng-48

ENG-02-0142-AD 


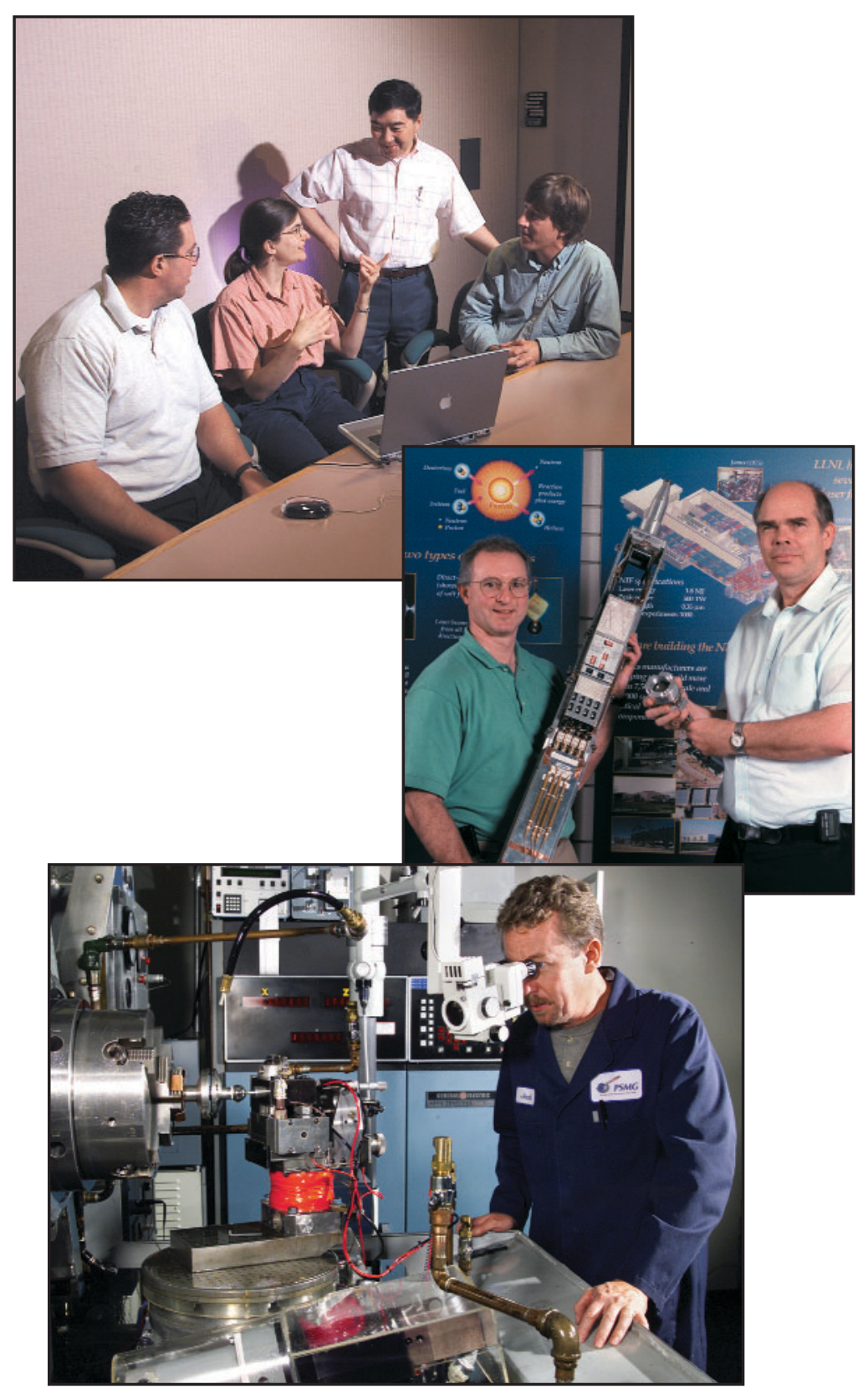

Contents .................................................

Message from the Associate Director........2

Profile of Engineering..............................4

2001/2002 Accomplishments..................10

New Ventures ..........................................34

Future Priorities..................................36

Honors, Awards, and Patents.................38

Engineering Statistics ............................44

Laboratory Statistics ...........................45 


\section{Message from the Associate Director}

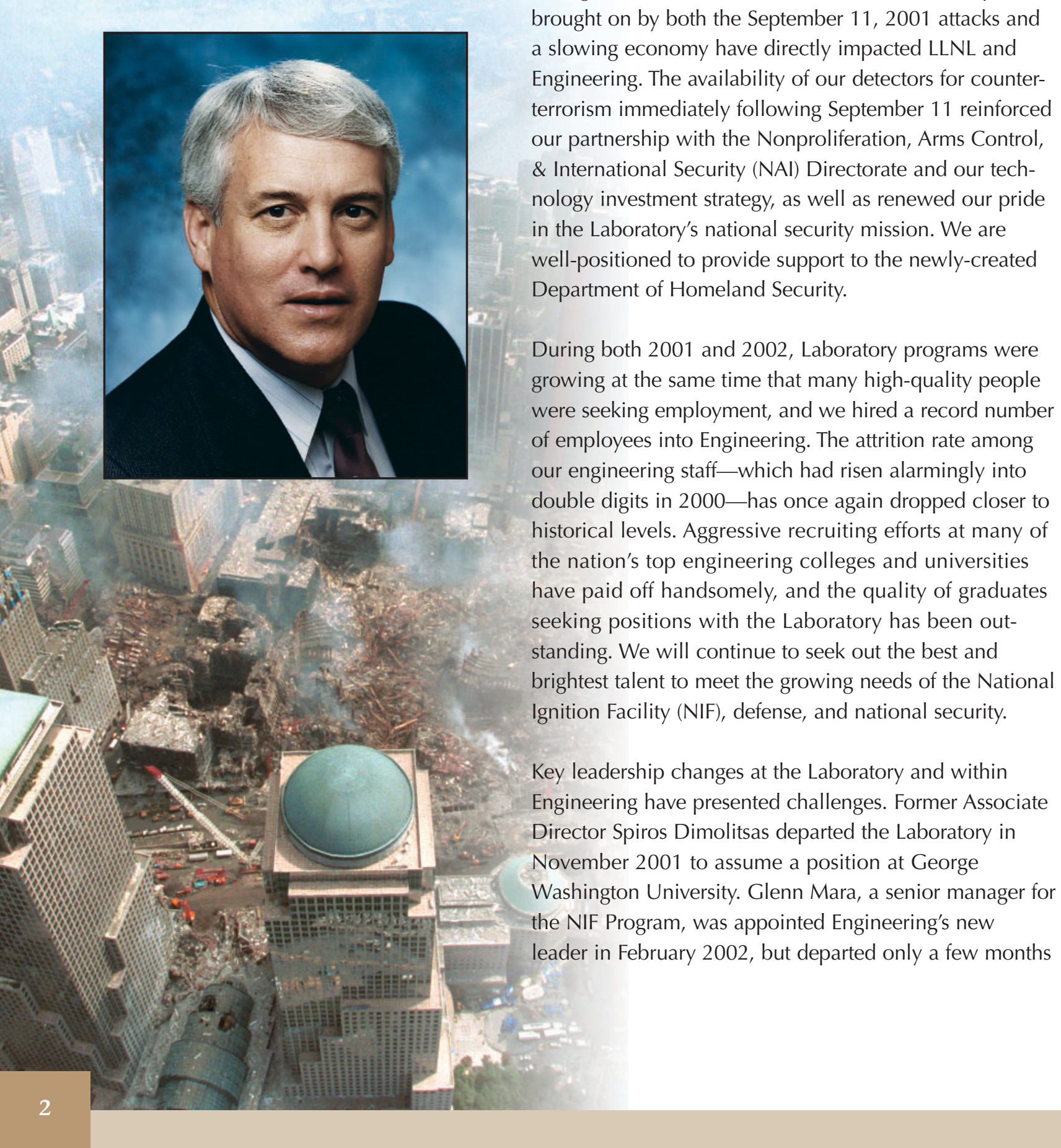

later when asked to serve as Laboratory Deputy Director for Operations by our new Laboratory Director, Michael Anastasio. I am gratified to report that despite these senior leadership changes, Engineering has continued to execute on its commitments to the programs thanks largely to the dedication and focus of our employees.

On the lighter side, the Laboratory celebrated its 50th anniversary in 2002, and we took the opportunity to remember Engineering's history and recognize the accomplishments of our people. We produced a handsome book, History \& Reflections of Engineering at Lawrence Livermore National Laboratory, and an awardwinning documentary video, "A Journey Through Time: 50 Years of Engineering at LLNL." Numerous retrospective lectures and presentations were given, and activities were capped in September by Celebration Week. We were treated to a series of addresses by visiting dignitaries, and we enjoyed sharing memories with Engineering alumni at our annual picnic.

Engineering personnel received significant recognition over the last two years from professional societies, universities, the government, and technical organizations. In 2002, we were key contributors on four of the Laboratory's five teams that received prestigious R\&D 100 Awards - indicative of the multidisciplinary spirit of Engineering and the Laboratory. Engineering personnel were awarded 29 patents in 2001 and 26 in 2002, bringing our total to well over 1000. Our Leadership Development Program and Project Management Initiative continue to attract emerging leaders and prepare them to assume responsibilities for managing people and projects. 



\section{Profile of Engineering}

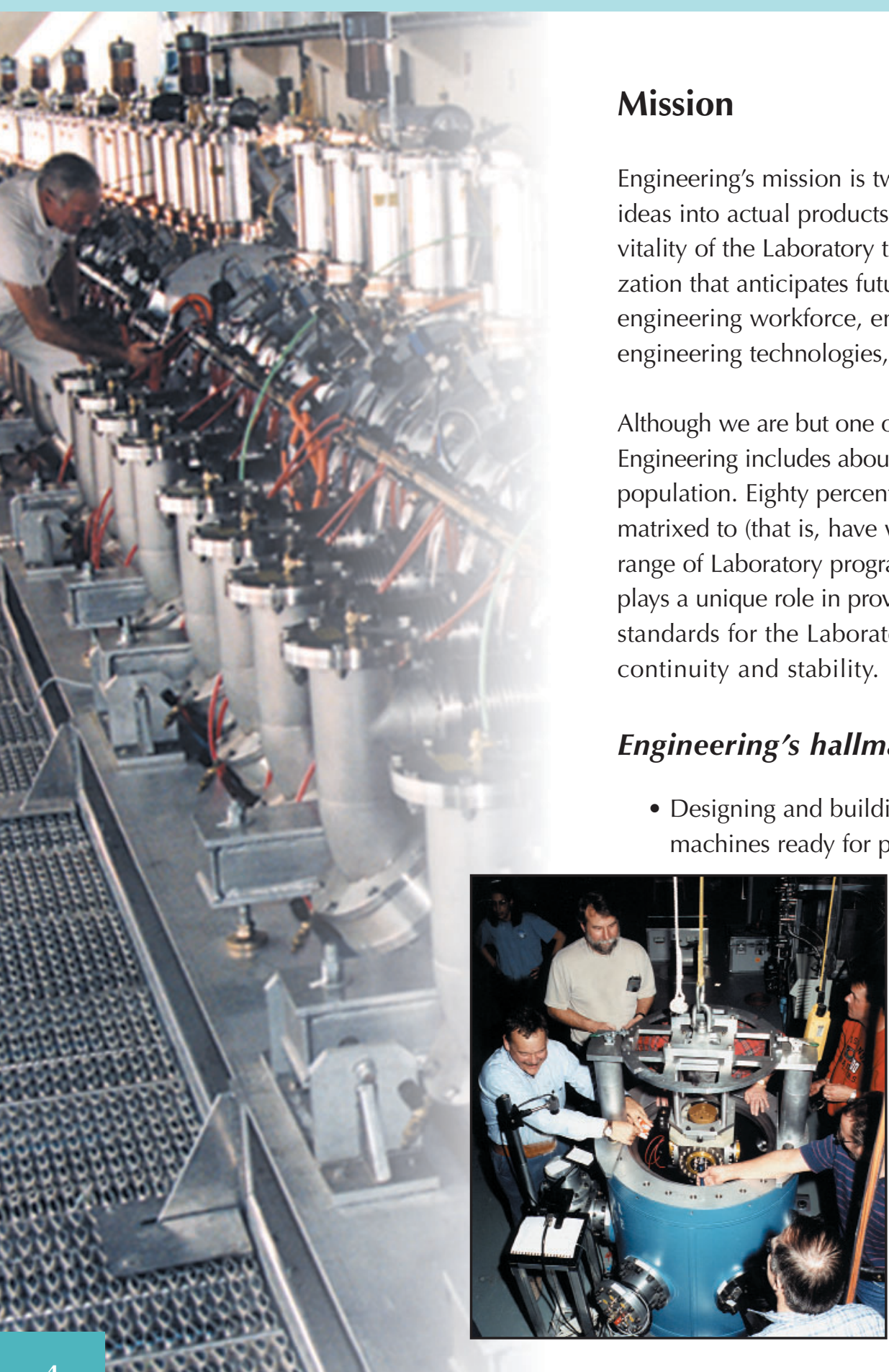

- Designing and helping construct most of the Laboratory's unique test facilities, such as those where weapons are environment- and/or performance-tested and facilities where new manufacturing processes are developed.

- Conducting research in advanced, broad-application technologies that enhance the Laboratory's ability to pursue its mission.

A profile of Engineering at LLNL can best be given in terms of three categories: our workforce, our technology areas of expertise, and the capabilities in our facilities and infrastructure.

\section{Organization}

The Engineering Directorate is organized into four Mechanical Engineering divisions, three Electronics Engineering divisions, and five Technology Centers. Working together, these divisions and centers form an Engineering organization that regularly takes on challenges to accomplish what would seem to be impossible.

Our current staff of over 2200 has expertise in mechanical, electrical/electronics, computer, nuclear, chemical, materials, civil, and other types of engineering. For customers inside and outside the Laboratory, Engineering personnel manage numerous large and small projects requiring complex interactions and a multidisciplinary approach. Engineering personnel simulate engineering systems, design engineering systems, and test systems performance. 


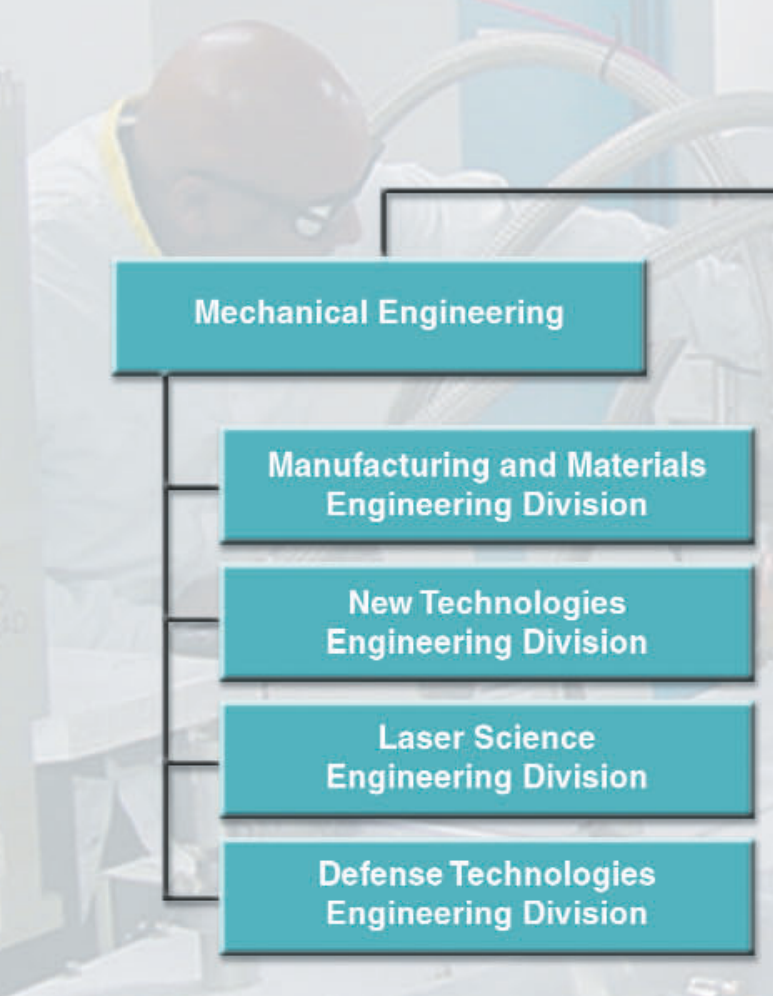

\section{Technology core competencies}

We undertake projects with high technical risk, integrate and extend technologies concurrently, and use the extremes of both ultrascale and microscale to achieve results. We call this "Xtreme Engineering." Such projects might include building massive structures but aligning them with extremely fine precision.

For example, Engineering employees are currently involved in building the National Ignition Facility (NIF), a stadium-size laser facility with more precision optics than all the world's telescopes combined, and which incorporates 5100 tons of steel structures aligned at one-hundredth-of-an-inch precision.
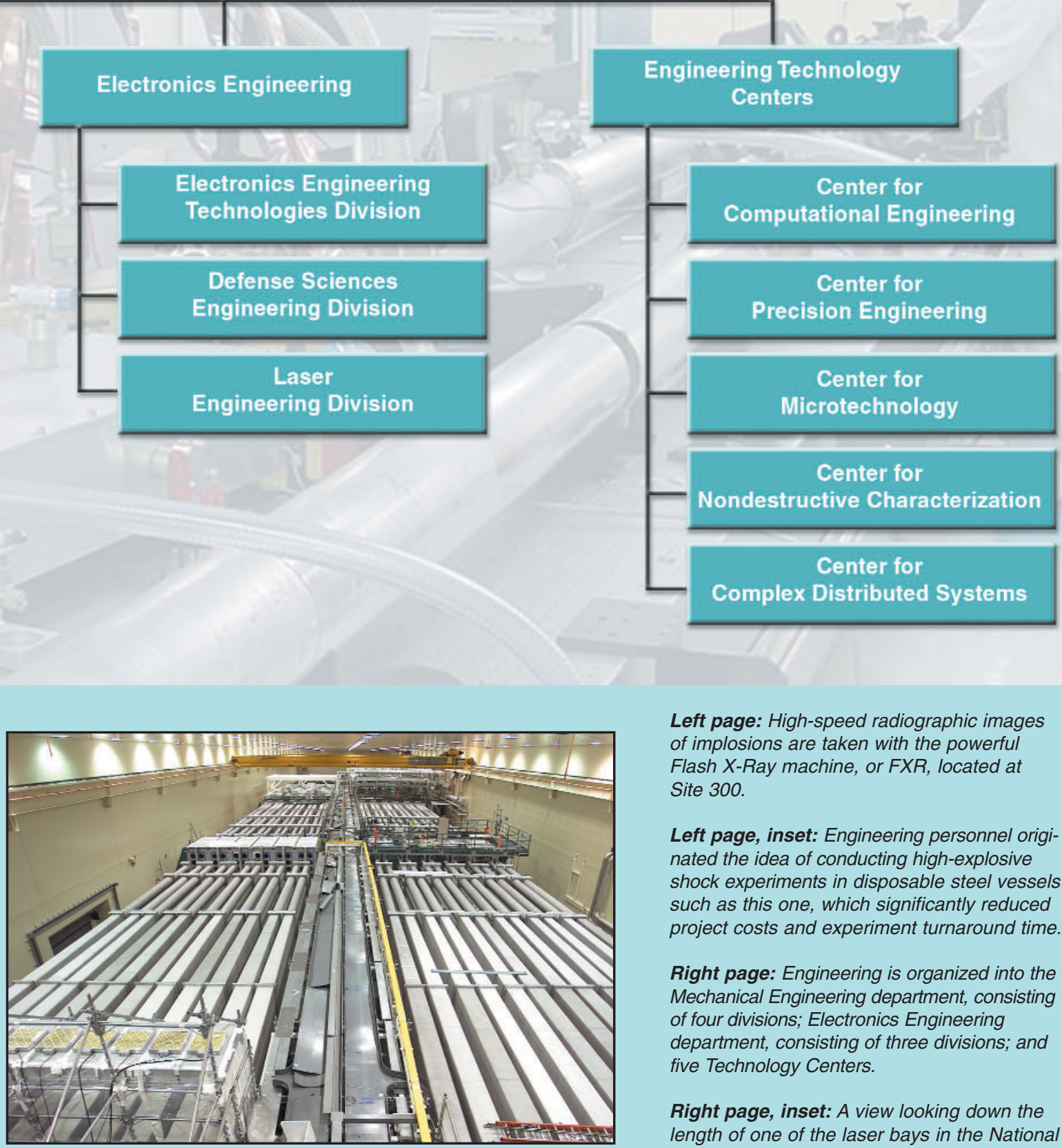

Left page: High-speed radiographic images of implosions are taken with the powerful Flash X-Ray machine, or FXR, located at Site 300

Left page, inset: Engineering personnel originated the idea of conducting high-explosive shock experiments in disposable steel vessels such as this one, which significantly reduced project costs and experiment turnaround time.

Right page: Engineering is organized into the Mechanical Engineering department, consisting of four divisions; Electronics Engineering department, consisting of three divisions; and five Technology Centers.

Right page, inset: $A$ view looking down the length of one of the laser bays in the National Ignition Facility. 


\section{Profile of Engineering}

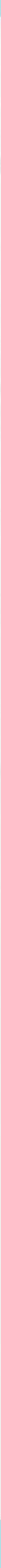




\section{and activity areas are:}

\section{Microscale engineering}

- Precision, brittle material fabrication

- High-precision optics

- High-precision diagnostic instruments

- Miniaturized, integrated analytical biological and chemical systems

- Medical microinstruments and microtools

- Genome sequencing instrumentation

- Optoelectronic communication devices

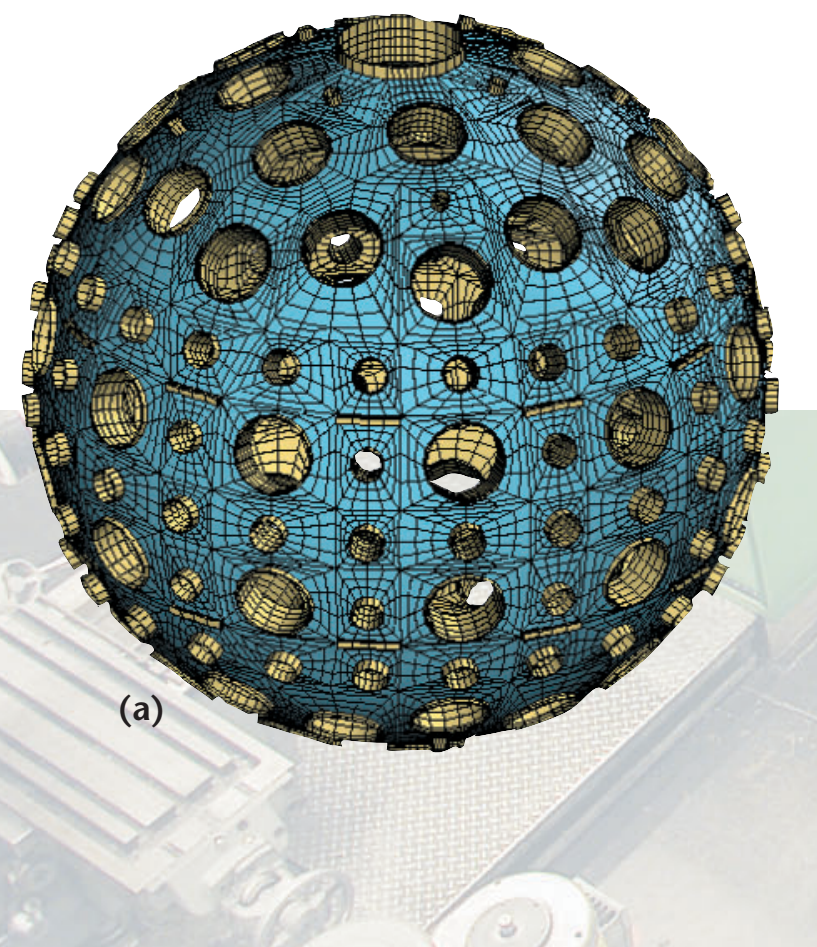

\section{Measurement science at extreme dimensionalities}

- Real-time data acquisition and processing

- Transient diagnostics

- Remote characterization and detection systems

- Ultralow-power, precision proximity radar

- Adaptive sensors and networks

- Nondestructive evaluation

- Accelerated materials aging

- Biomedical imaging

- Geologic signal processing and analysis

- Subsurface (including underground) imaging

- Environmental monitoring and characterization

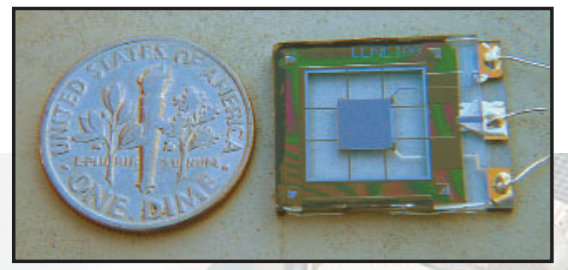

(b)

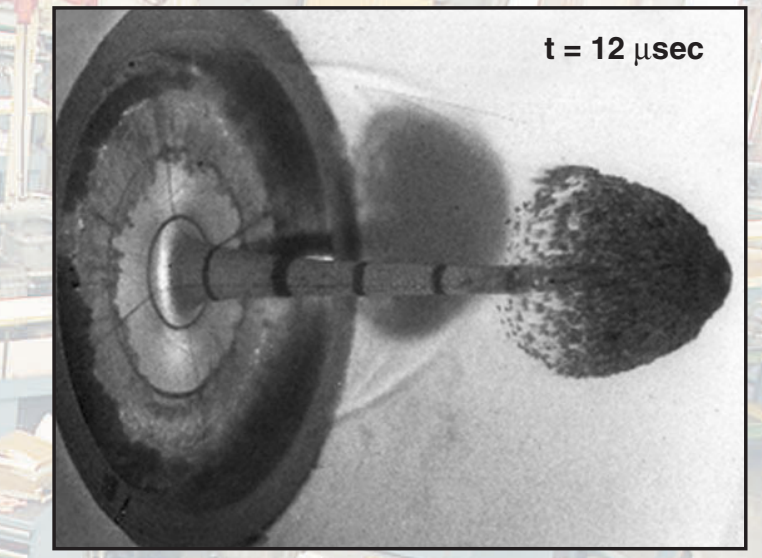

(c)

Left page: A modular, telephone-booth-sized line replaceable unit, or $L R U$, is installed into a NIF beamline.

Left page, inset: Deformable mirrors such as this one, used to correct aberrations in the NIF laser beamlines, must be fabricated and tested in a clean environment.

Right page, inset (a): The NIF target chamber was modeled using LLNL's NIKE3D and TOPAZ3D codes.

Right page, inset (b): Research into ever smaller sensors with lower power requirements led to the development of this wireless microaccelerometer, which measures only 15 millimeters square and 3 millimeters thick (pictured next to a dime for size comparison).

Right page, inset (c): Engineering often needs to model the behavior of materials at high pressures and strain rates, such as the jet captured in this high-speed photo of a shape charge. 


\section{Profile of Engineering}

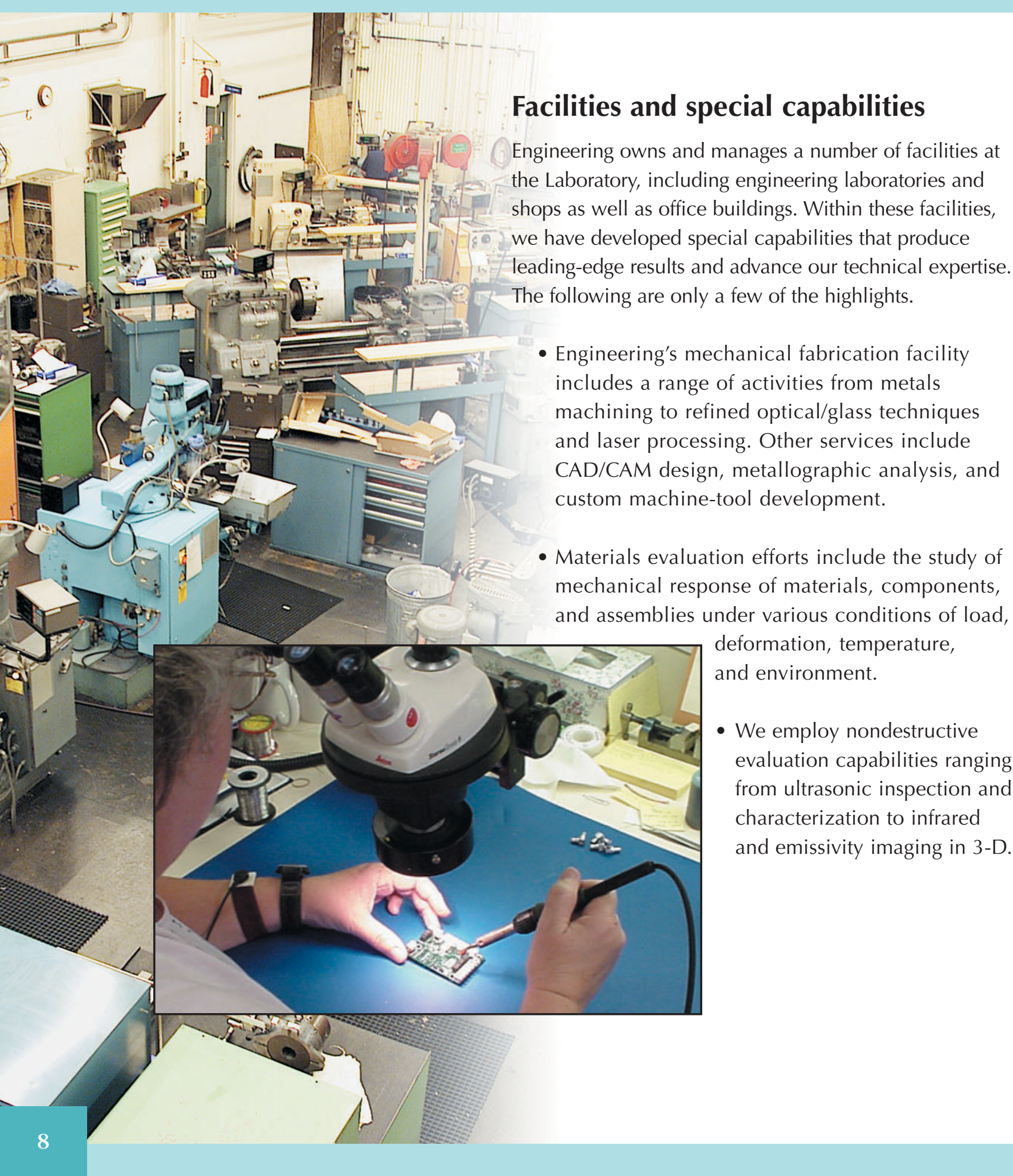

- Our electronics manufacturing facilities (which are ISO 9001:2000 quality certified) include central drafting, electronic fabrication/packaging, printed circuit board/surface mount technology, and the through-hole technology facility.

- Our microtechnology building houses 3500 square feet of Class 10-1000 clean rooms for micromachining, silicon microelectronics, III-V semiconductor optoelectronics, and guided-wave photonics. Other labs provide material characterization and device-testing capabilities, microscopic inspection, packaging, and electrical and optical testing of devices.

- Our high-pressure lab is one of the most complete high-pressure design, fabrication, and testing facilities in the world.

- Our abilities in plasma and high-power systems allow us to design, construct, and test total systems, including the necessary support circuits, subsystems, and software. 

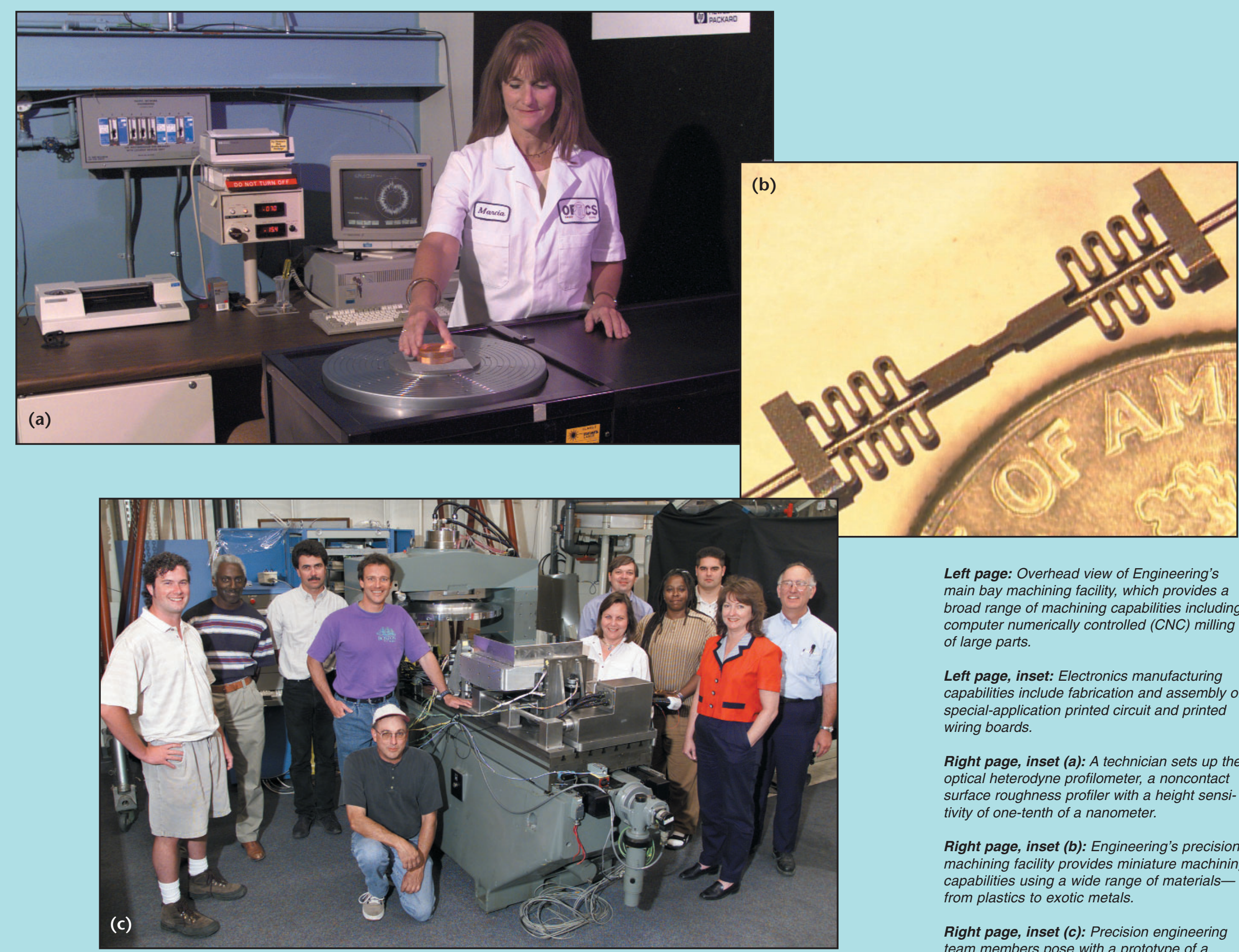

Left page: Overhead view of Engineering's main bay machining facility, which provides a broad range of machining capabilities including computer numerically controlled (CNC) milling of large parts.

Left page, inset: Electronics manufacturing capabilities include fabrication and assembly of special-application printed circuit and printed wiring boards.

Right page, inset (a): A technician sets up the optical heterodyne profilometer, a noncontact surface roughness profiler with a height sensitivity of one-tenth of a nanometer.

Right page, inset (b): Engineering's precision machining facility provides miniature machining capabilities using a wide range of materialsfrom plastics to exotic metals.

Right page, inset (c): Precision engineering team members pose with a prototype of a potassium dihydrogen phosphate (KDP) crystal finishing machine, developed at LLNL to produce high-quality optics for use in NIF. 


\section{1/2002 Accomplishments: W80 Life Extension Program}

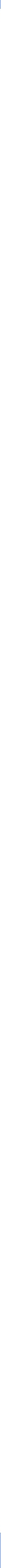






\section{1/2002 Accomplishments: JASPER Facility}

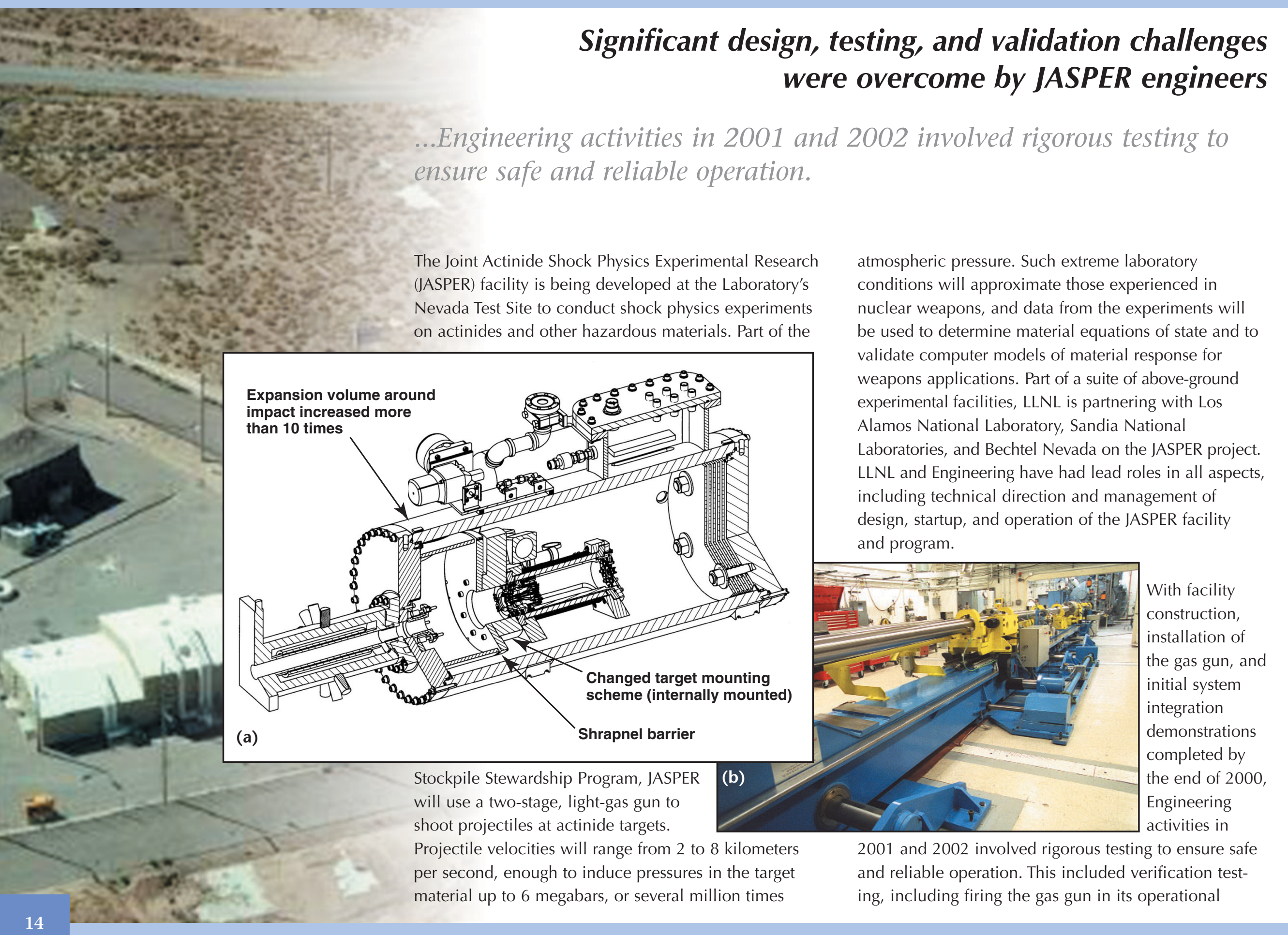





\section{1/2002 Accomplishments: NIF Beampath Infrastructure}

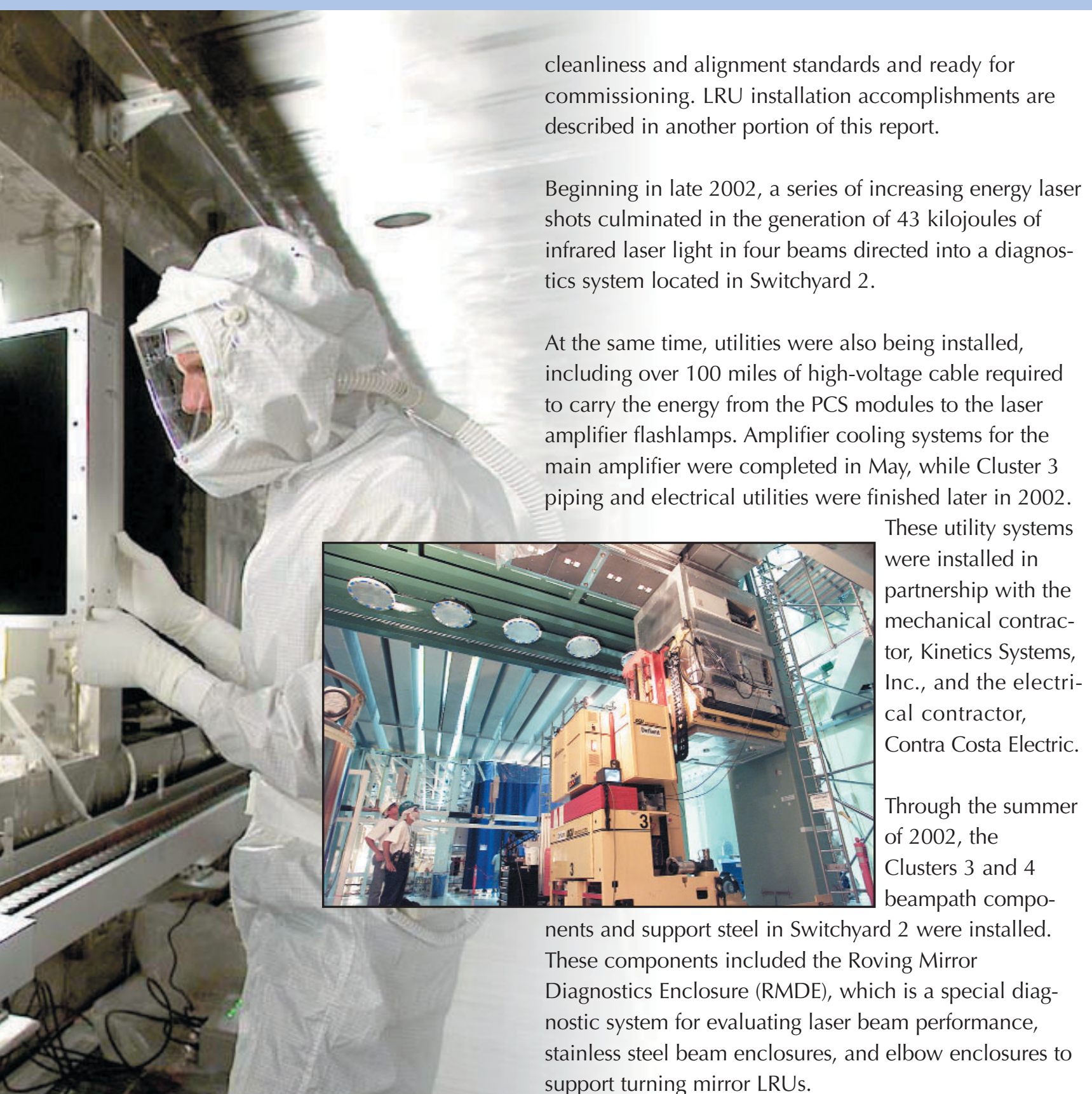

The first test shots in NIF—called "rod shots"—-began on October 15, 2002. Using all the main laser LRU systems and controls except the main amplifiers, light was successfully propagated all the way from the Master Oscillator Room through the preamplifier modules, the injection laser system, and the main laser beampath to the Switchyard 2 diagnostic calorimeters located in the RMDE.

Two months later, the first main laser system shot was fired in Laser Bay 2, which integrated operation of the beampath and its supporting utilities using all the Bundle 31 laser components and optics, power conditioning system, diagnostics, and computer control system. On December 11, a 13.4-kilojoule shot was fired with less than 1 percent variation among the four beams and an excellent energy balance, easily meeting the first NEL milestone requiring 10 kilojoules of laser energy. On December 17, the NIF Team successfully fired 43 kilojoules into the RMDE.

In preparation for first light to the target chamber in early 2003, a precision diagnostic system, which was used during the Beamlet prototype test program, is currently being installed and commissioned in Switchyard 2. The Final Optics Assembly (FOA) for the bottom "quad" of Bundle 31 was also installed on the target chamber. The FOAs house the special crystals and optics that convert the infrared laser light to ultraviolet light and focus it on the target at the center of the target chamber. Within the target area, the target positioner, target alignment sensor positioner, and other target experimental diagnostic packages are being installed on the chamber and commissioned. With all these systems installed and commissioned, NIF is planning to achieve its next NEL milestone 




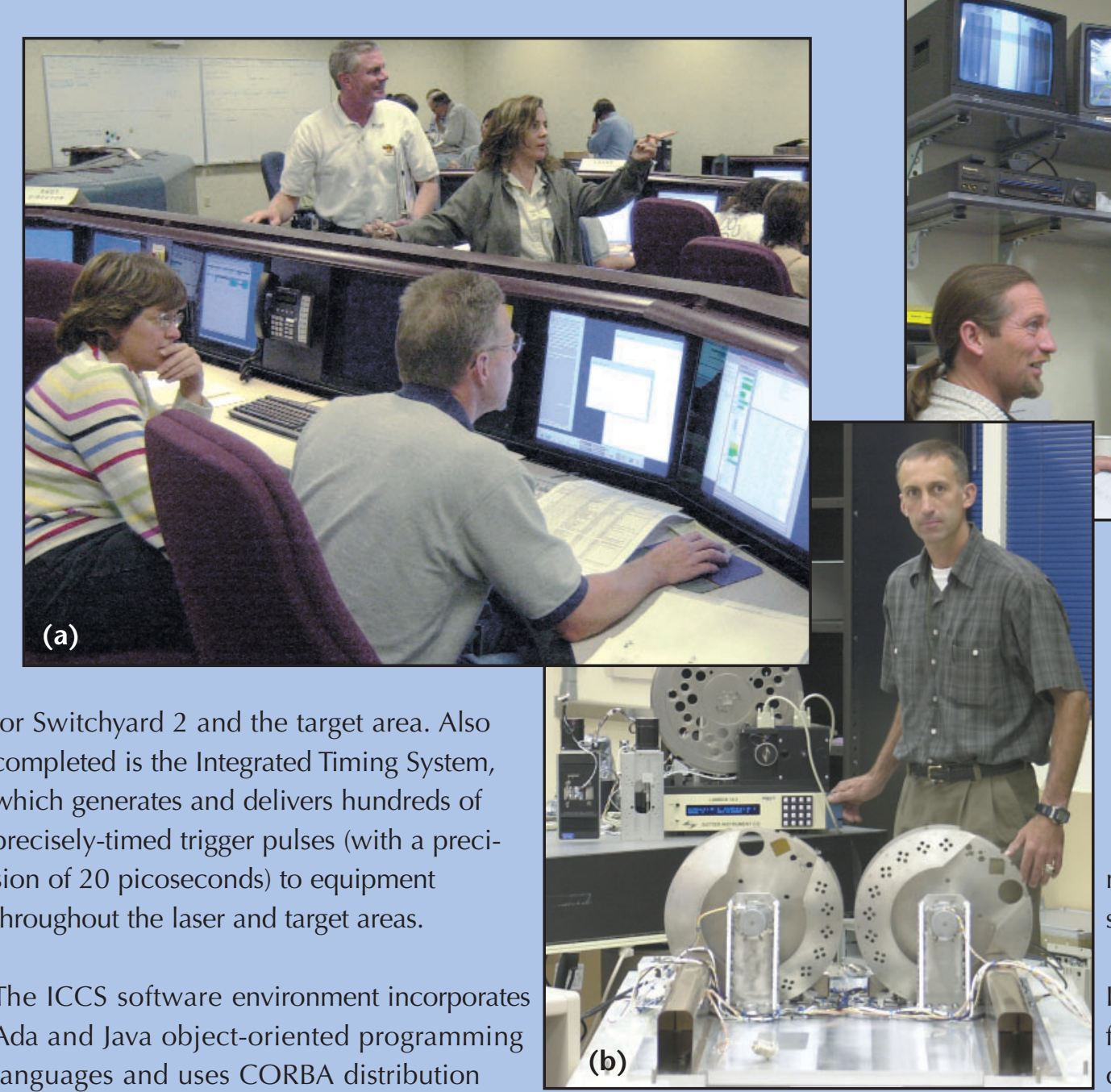

technology to enhance the openness of the architecture and portability of the software. During 2001 and 2002, incremental cycles of software construction and test have been carried out. Controls hardware and software were formally verified by offline tests in the ICCS Integration and Test Facility, followed by tests in integration laboratories using production laser equipment. After successful testing, the software is deployed to NIF and commissioned with the laser hardware. The team has met demanding production schedules and delivered using the control system. Two months later in December, another milestone was reached as amplified test shots produced more than 43 kilojoules of infrared light in Laser Bay 2. (c)

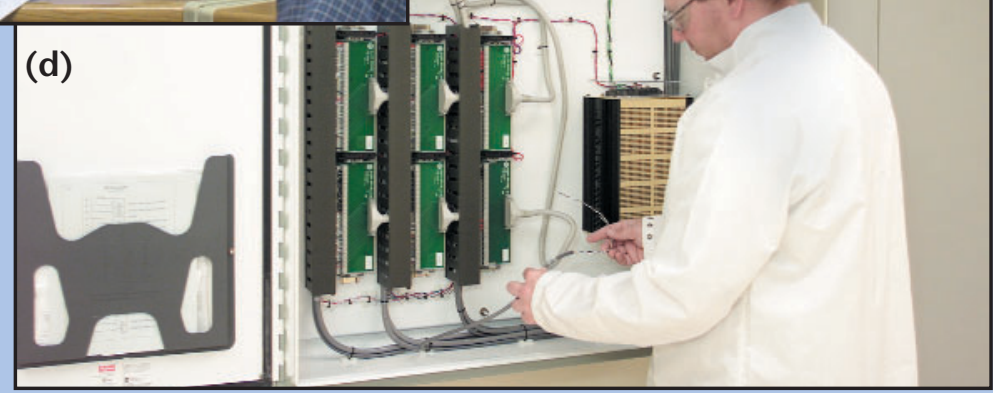

nearly two-thirds of the software to the facility.

In October 2002, the first NIF "rod shot" was conducted on-schedule

Left page: Dozens of control systems, such as this rack of motor controllers, have been installed in the NIF facility over the past two years.

Left page, inset: Automatic alignment of the the preamplifier module and input sensor is tested in the lab.

Right page, inset (a): Engineers and computer scientists at the ICCS Duty Engineer console prepare for laser shots.

Right page, inset (b): Fast filter pinwheels under test in the ICCS Integration and Test Facility.

Right page, inset (c): Power conditioning module under test in the Pulse Power Integration Lab.

Right page, inset (d): Safety interlock PLC field I/O installed in the preamplifier maintenance area will assure personnel safety from laser and high-voltage hazards. 


\section{1/2002 Accomplishments: Precision Manufacturing}

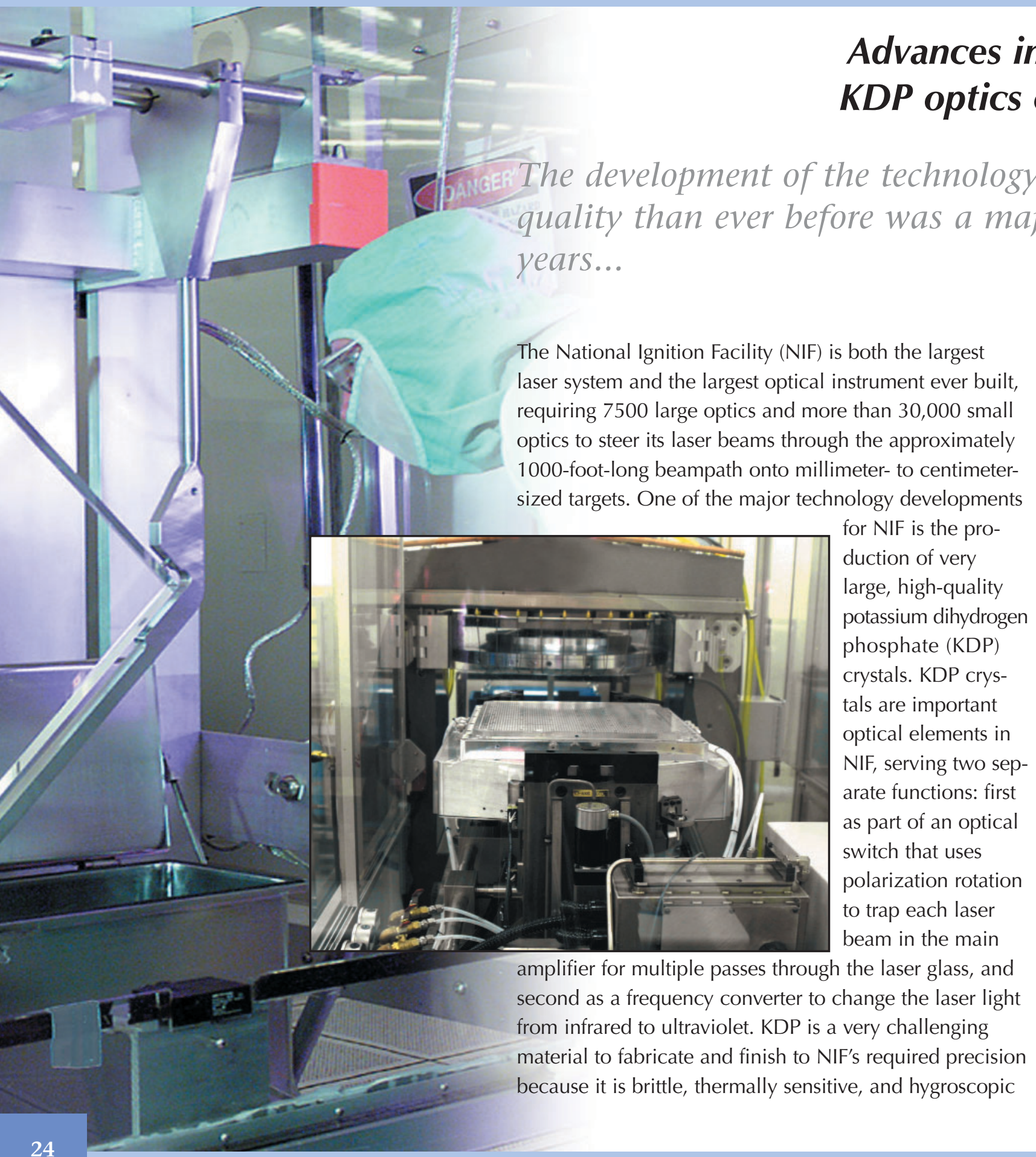

and so must be kept in a humidity-controlled environment at all times.

The development of the technology to fabricate KDP optics to higher quality than ever before was a major undertaking over the last two years, requiring advances in machining technologies applied to this special material. In order to meet NIF's exacting optics requirements, LLNL engineers, materials scientists, and laser technologists, in collaboration with our vendor, developed an elaborate fabrication process involving over 60 manufacturing operations to provide the greatest yield of precision KDP optics from each single large crystal. The diamond flycutting machines-designed and built by LLNL in partnership with industry and now installed at an industrial facility-employ a 100-kilogram aluminum fly-cutter spinning at 1000 rotations per minute on precision air bearings. Maximum error motion of the machines is less than 25 nanometers and asynchronous error motion is below 12 nanometers. The machine's speed can be controlled to better than 0.01 percent to maintain a crystal's flatness as it is being worked.

These achievements in machine design have made it possible to fabricate large-aperture (42 centimeters square) KDP optics that achieve the required surface 


\title{
2001/2002 Accomplishments: Biohazard Detection
}

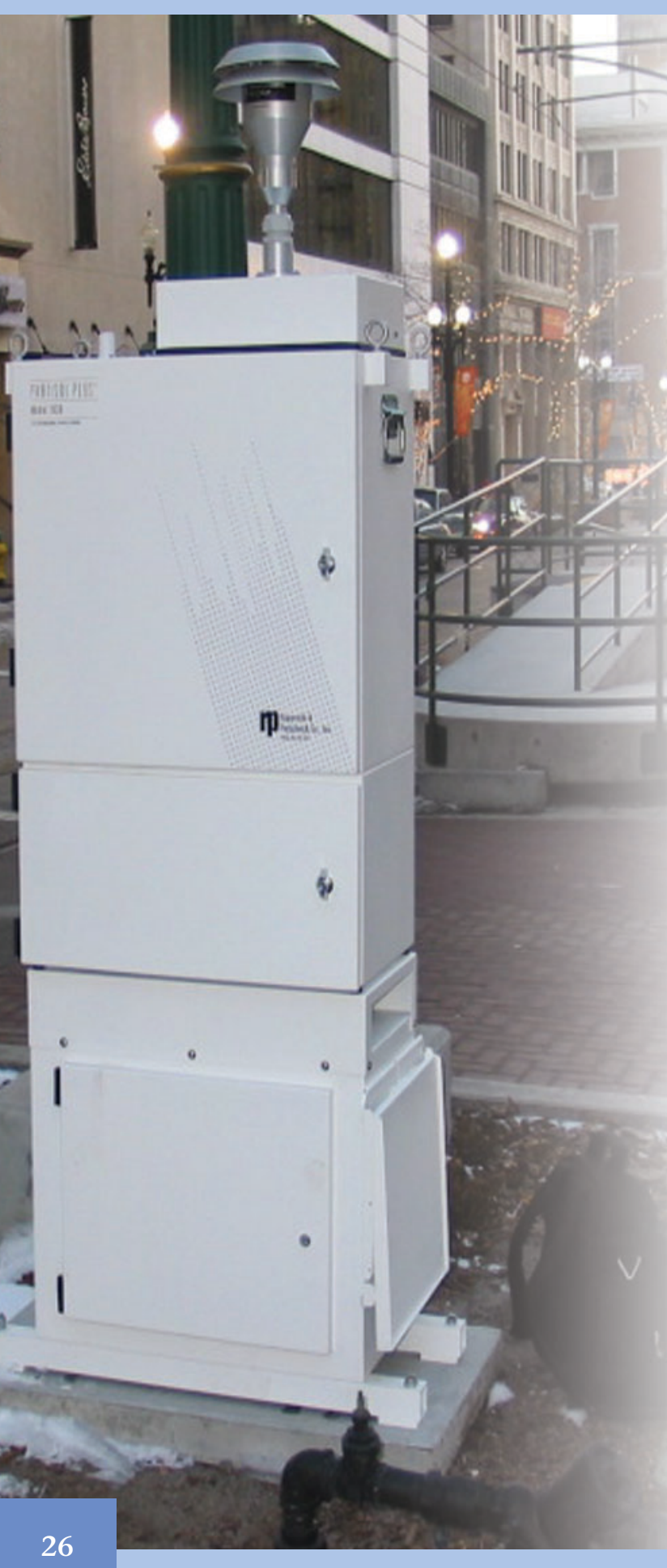

\section{BASIS deployment at the 2002 Winter Olympics helped assure public safety}

\author{
LLNL engineers were responsible for developing the communications \\ network to link together all the elements of BASIS.
}

Even before the September 11, 2001 terrorist and subsequent anthrax attacks, engineers and scientists from Lawrence Livermore and Los Alamos national laboratories were developing the Biological Aerosol Sentry and Information System (BASIS) to rapidly detect, identify, and characterize the release of biological agents. BASIS was developed as a part of the overall security for the 2002 Winter Olympic Games in Salt Lake City. The system includes distributed sampling units, a relocatable field laboratory (RFL) for analyzing samples, and a command and control center. BASIS reduces the time for

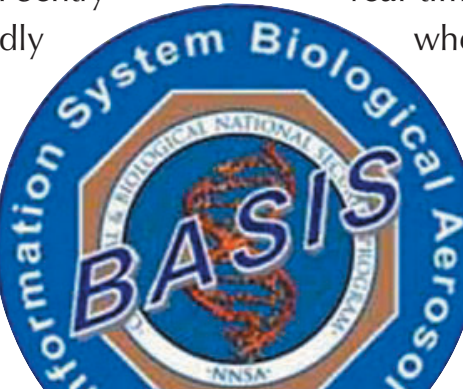
was also developed to bridge the gap to the nearest available Internet connection. Additionally, one of the team members created a software diagnostic to permit real-time monitoring of the BASIS network from anydetecting a bioagent release from days or weeks to less than a day, allowing a rapid public health response. LLNL engineers were responsible for developing the communications network to link together all the elements of BASIS.

The BASIS communications engineering team developed a versatile system architecture using virtual private network (VPN) technology in such a way that a variety of dial-up, cellular, wireless, and wired Internet connections could be supported. The VPN uses encryption and tunneling protocols to protect the BASIS network from hackers on the public Internet. A private wireless network
Because of increased security concerns after September 11, the BASIS program focused on early deployment and expanded coverage. The equipment suite was doubled so that half of it could be set up at the Olympics, while the other half was readied for transport and put on standby for deployment on 24-hour notice. As planned, BASIS was deployed at the 2002 Winter Olympic Games in support of federal, state, and local public health and law enforcement agencies. Sixteen distributed sampling units were located at sites in Salt Lake City and Park City where high concentrations of people were expected, while the RFL was set up at the Utah Department of Health. The system was operated successfully around the clock for over five weeks.

In the coming year, the BASIS communications team will focus on developing a new communications module that combines the functions of a VPN router, a next-generation cellular modem, and a wireless local 



\section{1/2002 Accomplishments: Micro Fuel Cell}

\section{Microfluidic fuel processors promise miniature power sources}

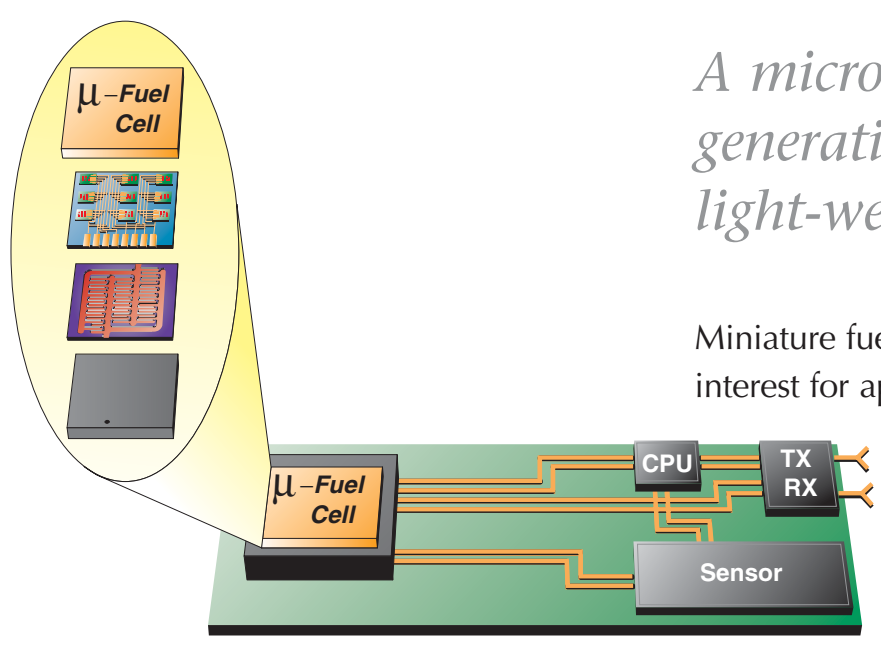

A microfluidic device technology enabling generic hydrogen generation...will lend itself to miniaturization for extremely compact, light-weight systems.

Miniature fuel cells have recently experienced renewed interest for applications in portable power generation. Portable power sources remain critical for all aspects of the military, weapons testing, and intelligence communities. While batteries have become a minor hindrance in the case of consumer portable electronics, they are simply not adequate for the advanced applications of remote reconnaissance, intelligence gathering, and telemetry. New power sources are required, with many of these having specific performance

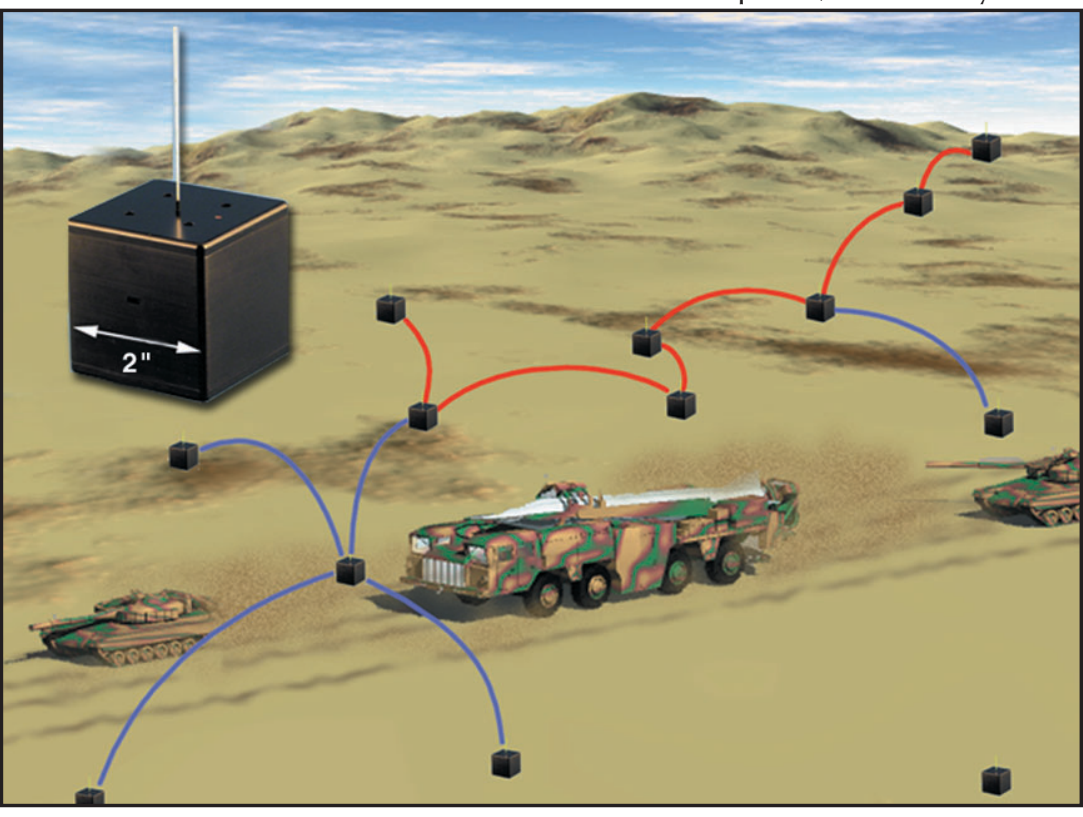
criteria for the direct application. A lighter-weight, longer-lasting power source provides new functionality to missions of all kinds, promising long-term cost benefits to all government agencies while enabling new levels of safety and security for personnel in the field.

Fuel cells store energy as fuel rather than as an integrated part of the structure of the device, as is the case with batteries. Current proton exchange membrane (PEM) fuel cells are limited to 3-15 percent methanol solution, thereby limiting their power and energy density. Our approach is to reform the methanol in a separate microreactor, convert it to hydrogen, and feed the hydrogen to the fuel cell. This approach allows us to exploit the very high energy densities of liquid fuels, using 50 percent methanol-water mixtures; higher concentrations may be possible by using novel water recovery designs. A microfluidic device technology enabling generic hydrogen generation will significantly extend the operating time of virtually any portable fuel cell power source, but most importantly, will lend itself to miniaturization for extremely compact, light-weight systems.

Our goal has been to design, fabricate, and test a microfluidic fuel processor for hydrogen generation for portable fuel cell power sources in order to reform hydrocarbon-based fuels having high specific energy content. With the hydrogen generation of the microfluidic fuel reformer, an integrated power solution targeting the 0.5-20-watt range may be realized. We have made significant advances by successfully depositing sputter-coated nickel and copper-oxide catalysts onto a reactor's microchannels and nanoporous membranes. Experiments performed using different flow patterns have yielded 


\section{(1) nin}

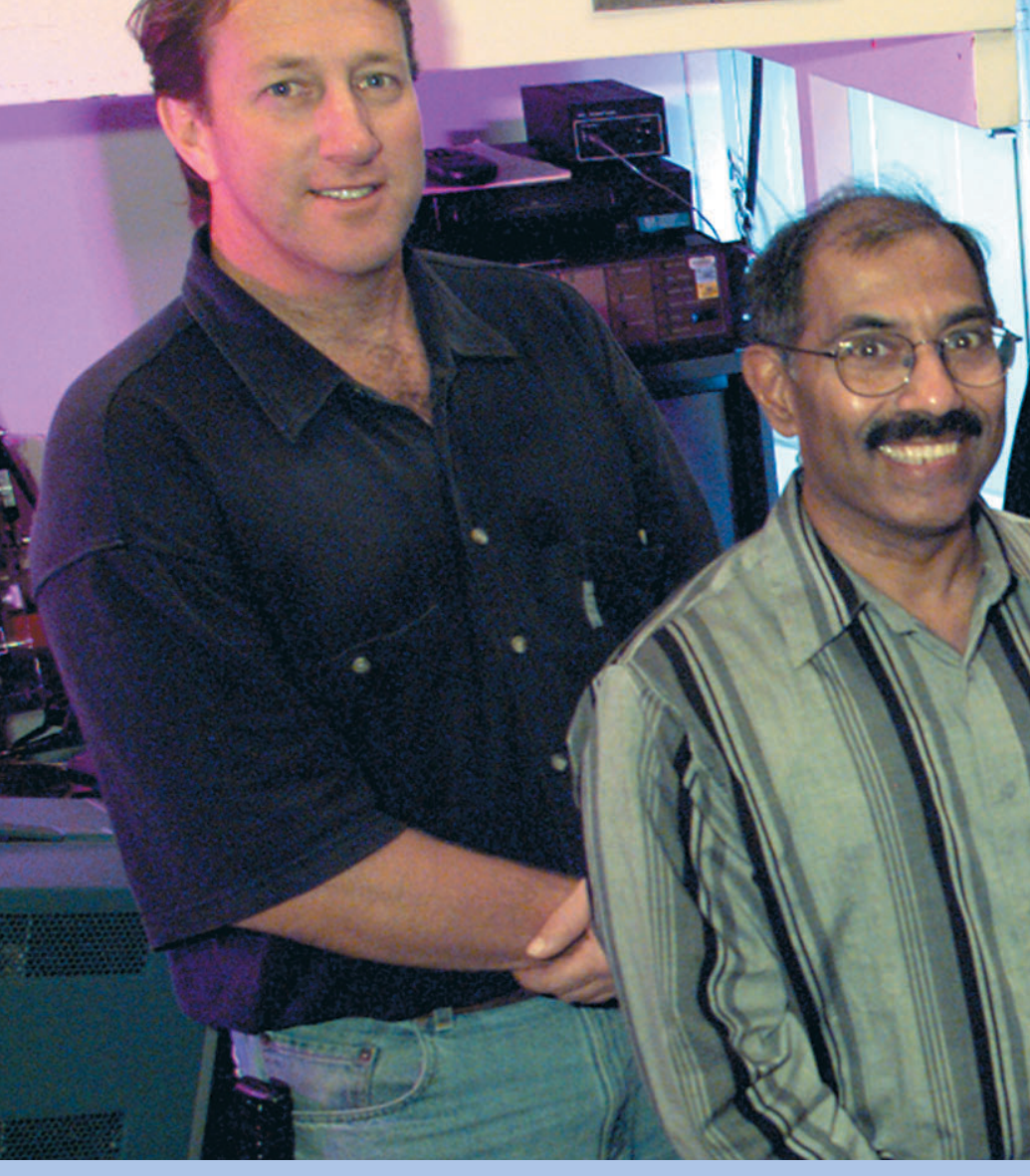

methanol conversions as high as 44 percent. Further experiments are under way to determine the performance of an improved reactor design.

In the future, continuing efforts will result in a thermally integrated microdevice comprising a microreformer converting methanol to hydrogen, and a fuel cell delivering 500 milliwatts of power output.
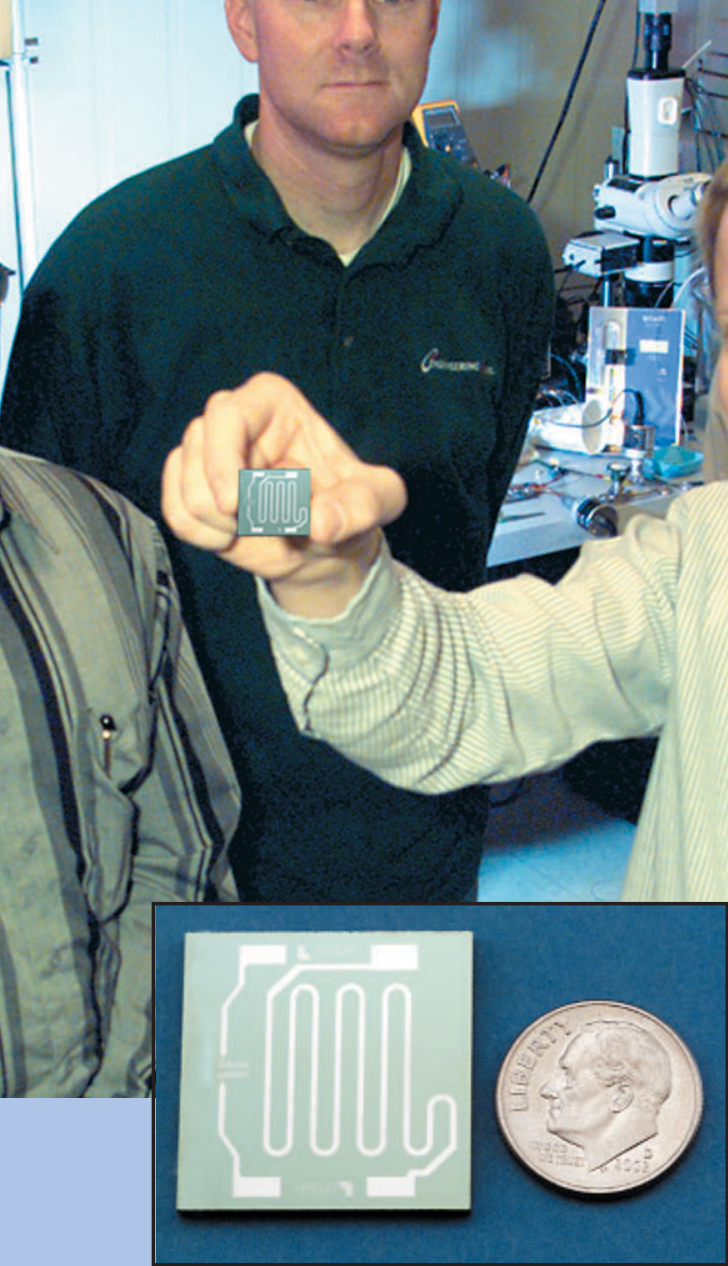

in
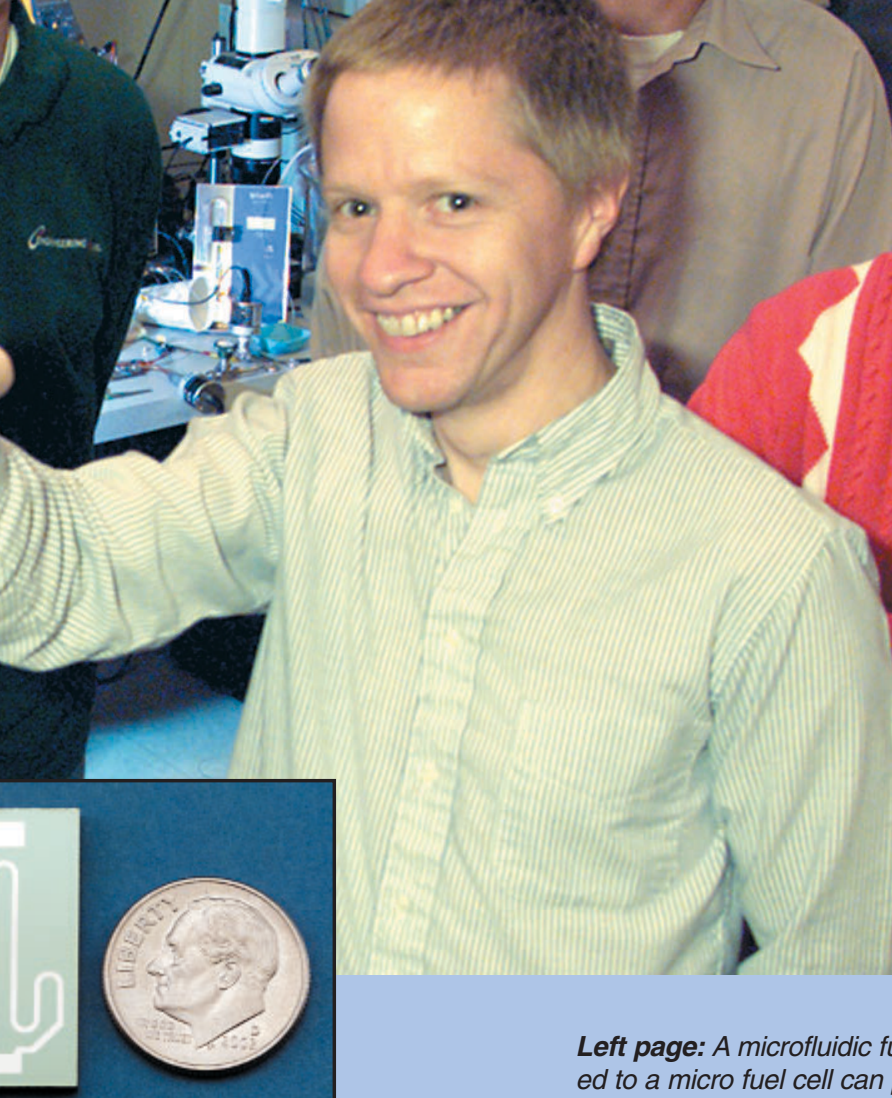

Left page: A microfluidic fuel processor connected to a micro fuel cell can provide a long-lasting. light-weight power source for unattended sensors.

Right page: Fuel processor development team members (left to right): Jeff Morse, Ravi Upadhye, Tim Graff, Dave Sopclak, Mark Havstad, and Alan Jankowski.

Right page, inset: A fuel cell microreactor is pictured next to a dime to show scale. 


\title{
2001/2002 Accomplishments: Computational Engineering
}

\section{Computer simulation capabilities have become crucial to national security and infrastructure research}

\author{
Initially only an adjunct to physical tests, [computational engineering] \\ capabilities are now central constituents of our work.
}

(a)

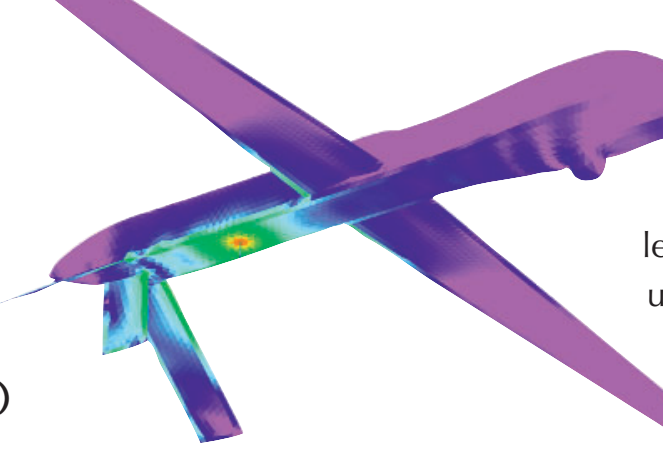

Computational engineering, which is the creation and use of numerical models to help understand and characterize the behavior of a component or system, is used extensively to both create futuristic leading-edge technology as well as develop greater understanding of existing engineered and natural sys-

tems. The national security mission of the Laboratory has motivated and supported much of Engineering's investment in simulation tools, and that trend has continued over the last two years. Initially only an adjunct to physical tests, these capabilities are now central constituents of our work.

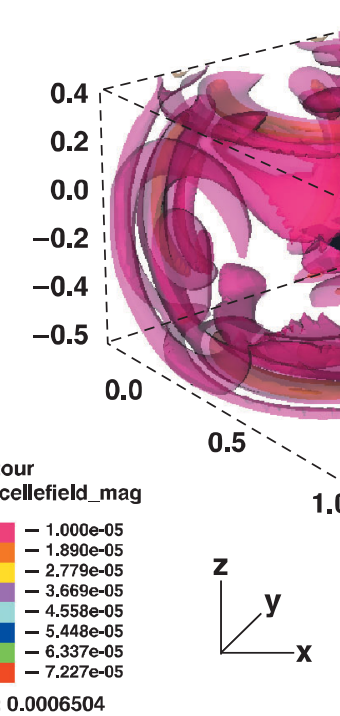

The ParaDyn code for nonlinear structural dynamics has been widely used within ongoing nuclear weapon life extension proji ects both here and at Los Alamos National Laboratory. We have used and supported Defense and Nuclear Technologies' ALE3D hydrodynamics code for engineering studies such as 0.5 $L^{y}$ $1.0 \cdot$ -

(b) code to improve sensor sensitivity and efficiency. The communications links between Department of Defense (DOD) assets during critical operations are being addressed by an effort to predict the electronic battlefield environment. Also, the design of the next generation of Department of Defense mixed-signal systems (or systems-on-a-chip) is being addressed by applying an in-house developed code to high-frequency chip designs, thus integrating electromagnetic simulations with circuit models.

In addition to national security applications, we are also using state-of-the-art, sophisticated modeling capabilities to examine aspects of the nation's constructed infrastructure. We are currently simulating the Morrow Point Dam in Colorado in a study sponsored by the U.S. Bureau of Reclamation. To better characterize the seismic performance of this segmented concrete arch dam, not only are the dam and reservoir being modeled, but also the surrounding topography. The model is first gravity-loaded to establish the hydrostatic load response of the dam. Then the excitation of a representative seismic event is applied at the base of the model, and the resulting wave propagation and response of the dam and reservoir are computed. This model captures the effects of potential wave diffraction or focusing due to the topography. Also, the loading on the dam is more realistic as its periphery is not 
uniformly excited. These efforts at increased fidelity have attracted the attention of academic researchers pursuing similar work.

\section{Seismic} excitation ᄀHethly
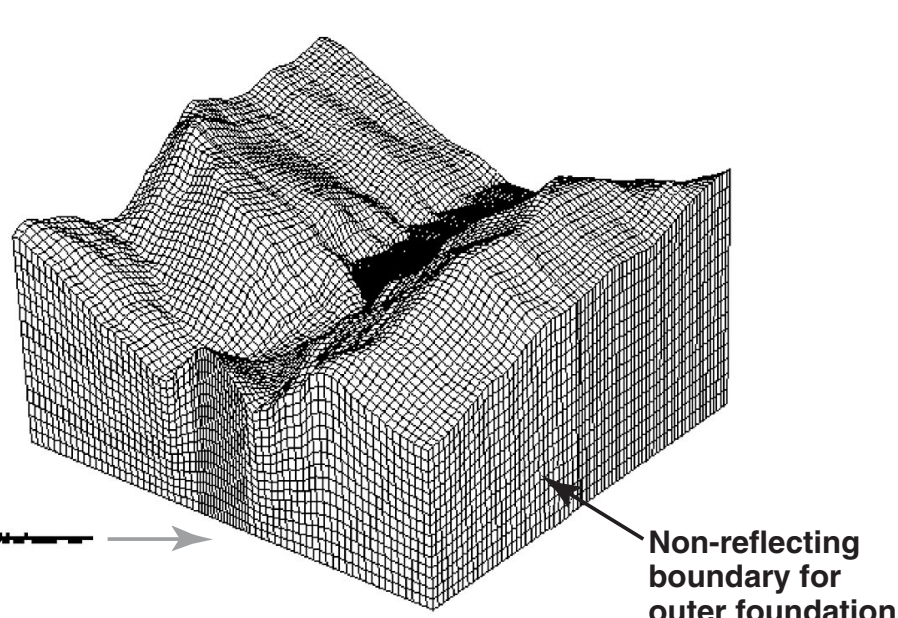

DYNA3D Seismic Analysis outer foundation

outer foundation
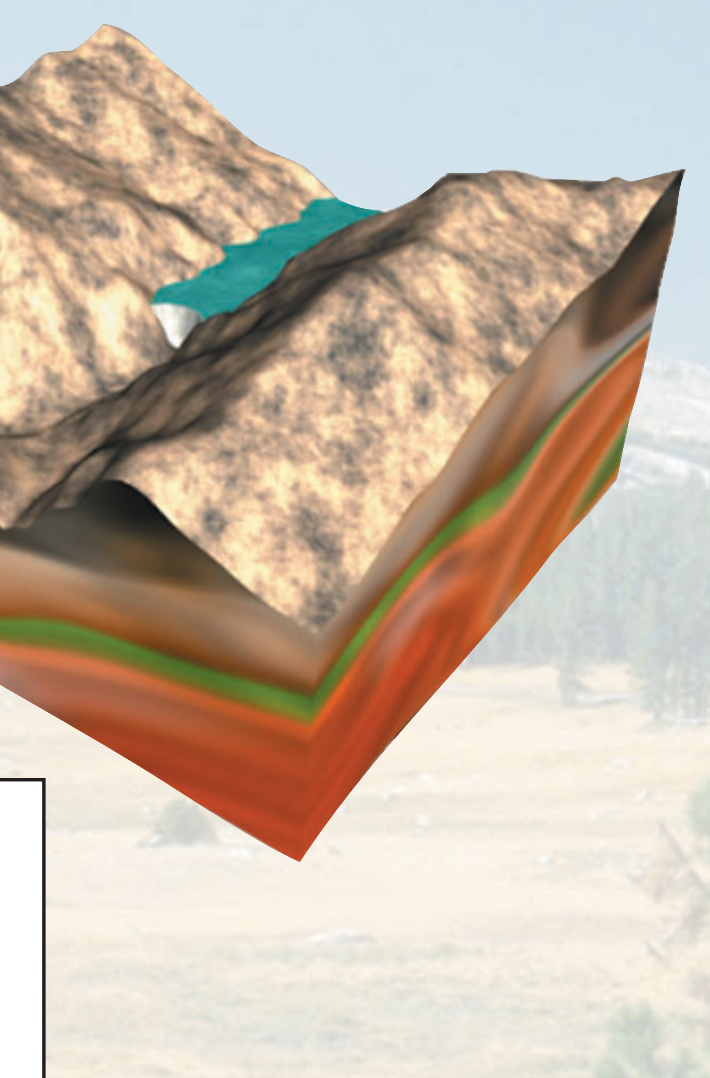

Left page, inset (a): LLNL's EIGER code suite is used to predict the installed systems performance of key $D O D$ assets. Here, the induced surface current on an unmanned air vehicle is shown. The radiation performance of this system can then be determined and optimized.

Left page, inset (b): The EMSolve tools are being applied to the challenging problem of mixed-signal systems design. The field distribution around a high-frequency transmission line is shown in this figure. From this analysis, coupling to other components and circuits can be determined.

Right page: An advanced finite element model of the Morrow Point Dam represents the dam, reservoir, and local topography in order to capreservoir, and local topography in order to cap-
ture their interactions during an earthquake. 


\section{1/2002 Accomplishments: Facility Improvements}

\section{Consolidation of electronics and mechanical fabrication facilities reduces costs while increasing efficiencies}

Consolidation of Engineering fabrication into the Building 321 complex is eliminating redundancies and making Engineering more cost-effective.

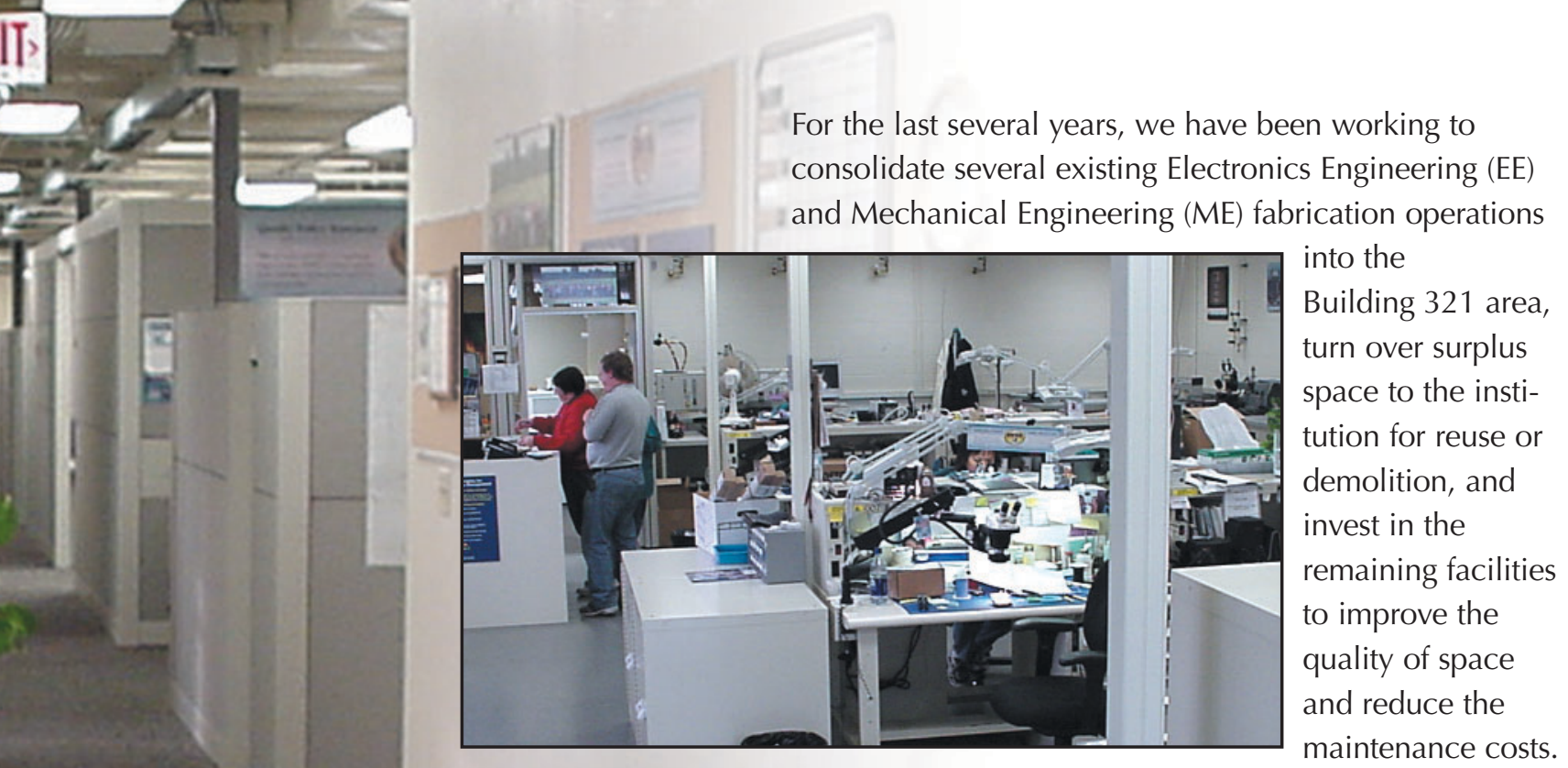

One of the main goals of this plan is to reduce the money Engineering spends each year to manage its facilities, which results in a corresponding reduction in the Organization Facility Charge (OFC).

The fabrication consolidation efforts have included moving EE fabrication from Building 141, Bay 1 to Building 321, moving the EE fabrication capabilities from Building 438 into Building 321, vacating Trailer 4326 (which was subsequently demolished), and moving the EE drafting group from Trailer 1481 to Building 321. This has allowed us to return Building 438 to the institution, while space in Building 141 and Trailer 1481 has been converted for other purposes. For example, a part of Building 141 that was formerly a high-bay area has been renovated with new modular offices, a conference room, and new bathrooms with showers. These improvements were targeted at creating high-quality space for Engineering personnel awaiting their security clearances.

In Building 321, improvements abound. Renovation efforts have provided an opportunity to install more environmentally friendly processes. By collocating EE and ME activities, duplicate plating equipment was eliminated. By upgrading equipment, the Building 321 welding shop was consolidated into approximately one-third of its original space, yet lost none of its capabilities. The precision machining group now enjoys a much larger area.

Additional benefits of the consolidation have been increased cooperation between previously separate EE and ME groups, a growing sense of Engineering team spirit, and improved morale amongst employees because of more efficient and capable work spaces. Now that they share facilities, the two fabrication groups are beginning to explore ways to share equipment and expertise-always with the goal of streamlining processes and increasing capabilities to support the Laboratory's programs. 
The Engineering Directorate has begun a major effort to prepare for the future fabrication, assembly, and characterization of targets to be fielded on high-power laser systems such as the National Ignition Facility. Called the Mesoscale Initiative, it has as its goal the development of capabilities needed to fabricate target assemblies for the Defense and Nuclear Technologies High-EnergyDensity Experimental Science (HEDES) Program. A number of these targets will require surface finishes in the 50-100 nanometer range, and surface features approaching one micrometer. Targets could have planar,

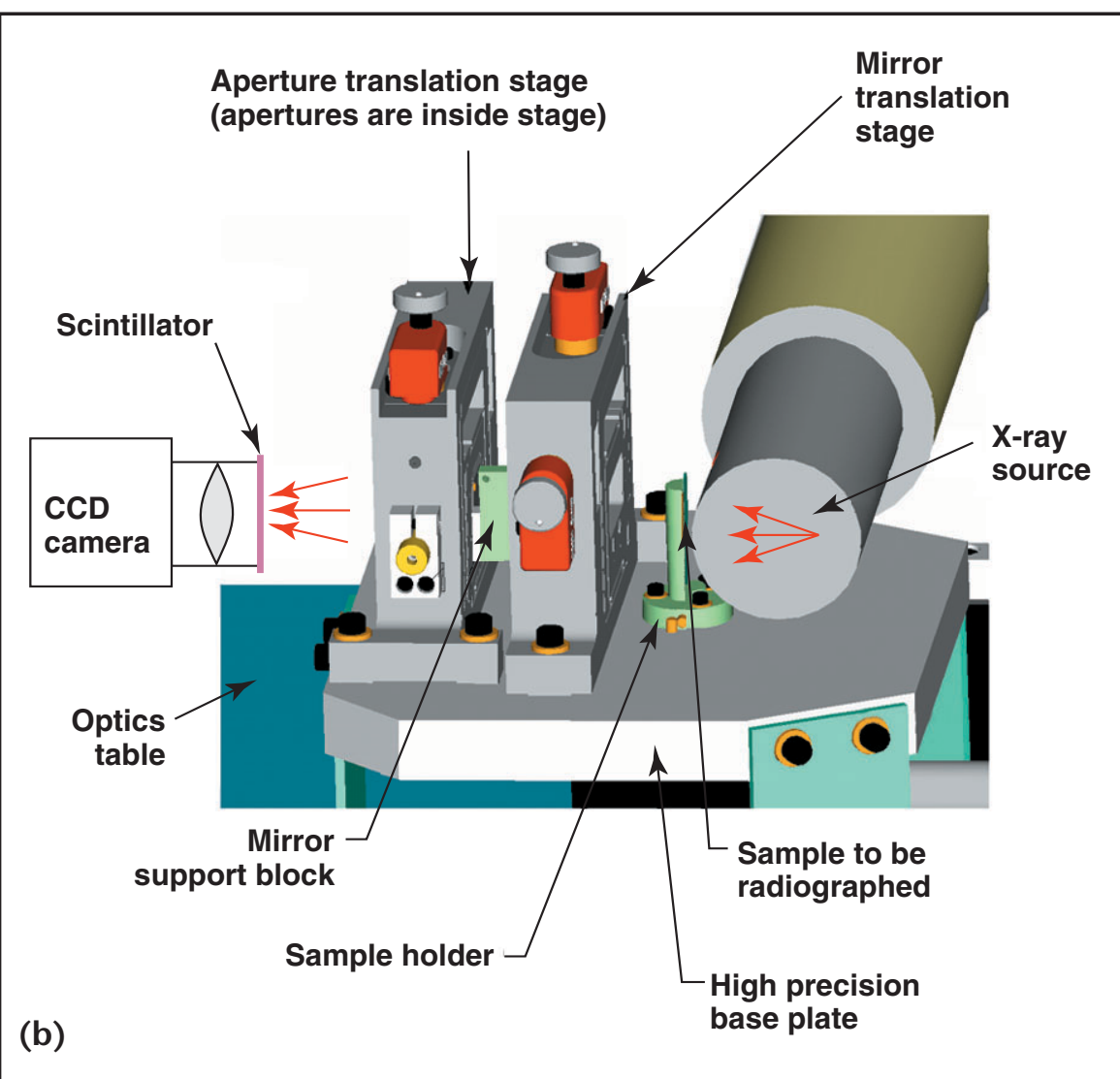
cylindrical, or spherical geometries in materials that vary from very low-density foams such as aerogels, to high-density, high-Z shells serving as high-pressure fuel capsules. The targets could have 1-, 2-, or 3-D features on their surfaces, with feature size in the micrometer to tens-of-micrometers regime. The HEDES share of the NIF laser test shot schedule amounts to 200 to 300 shots a year; of that number, we estimate that 80 to 90 percent of the targets on those shots can most likely be produced with extensions to existing capabilities. The Mesoscale Initiative is focused on the more difficult targets remaining. Therefore,

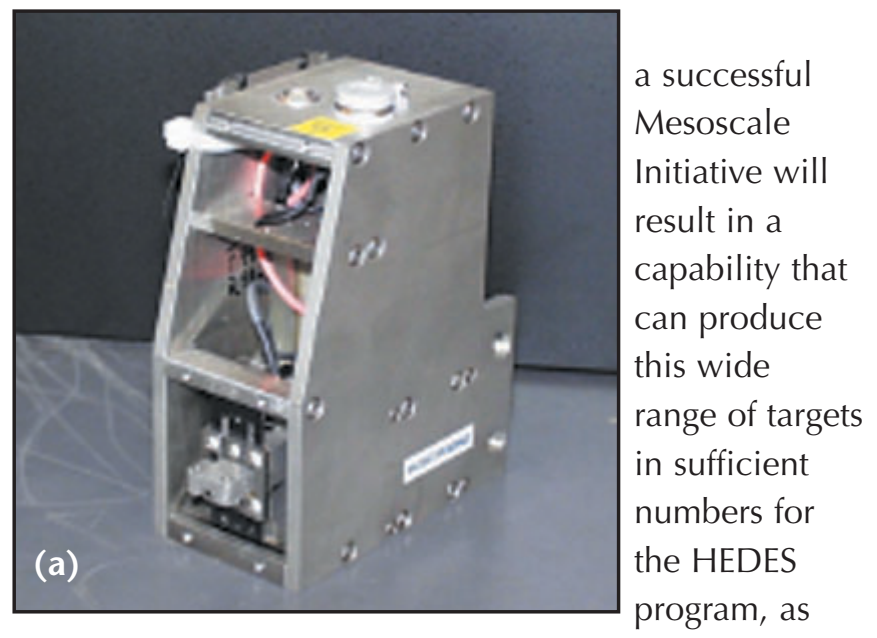

well as provide capabilities to the inertial confinement fusion (ICF) and outside user community for their target needs. To reach that end, we are coordinating various research and technology efforts to ensure the proper capabilities are being developed and to do feasibility studies of new approaches to yield these capabilities.

Fabricating targets is just part of the process. Once fabricated, the targets (which are usually made up of several components) must be assembled and characterized. Thus, the Initiative has six elements: material synthesis, material removal, material deposition, metrology of components, assembly, and characterization of the assembly.

In FY01-02, Engineering successfully proposed three Laboratory Directed Research and Development (LDRD) Exploratory Research (ER) projects that are critical to the Mesoscale Initiative. The first LDRD project is a continuation of a mid-year proposal, proposed to design and build an x-ray microscope capable of characterizing small (approximately 1 centimeter) targets to submicrometer resolution. A second LDRD is studying the 
enhancement of a fast servo tool to be added to the $\mathrm{z}$-axis of a diamond turning machine. By increasing the speed this tool can move in and out, we can greatly enhance the material removal on complex, 3-D features. The third LDRD is studying the material removal characteristics of an ultra-short pulse laser. Here, experiments are coupled to modeling efforts to see if a deterministic behavior can be identified and if these lasers are capable of delivering the surface finishes required.

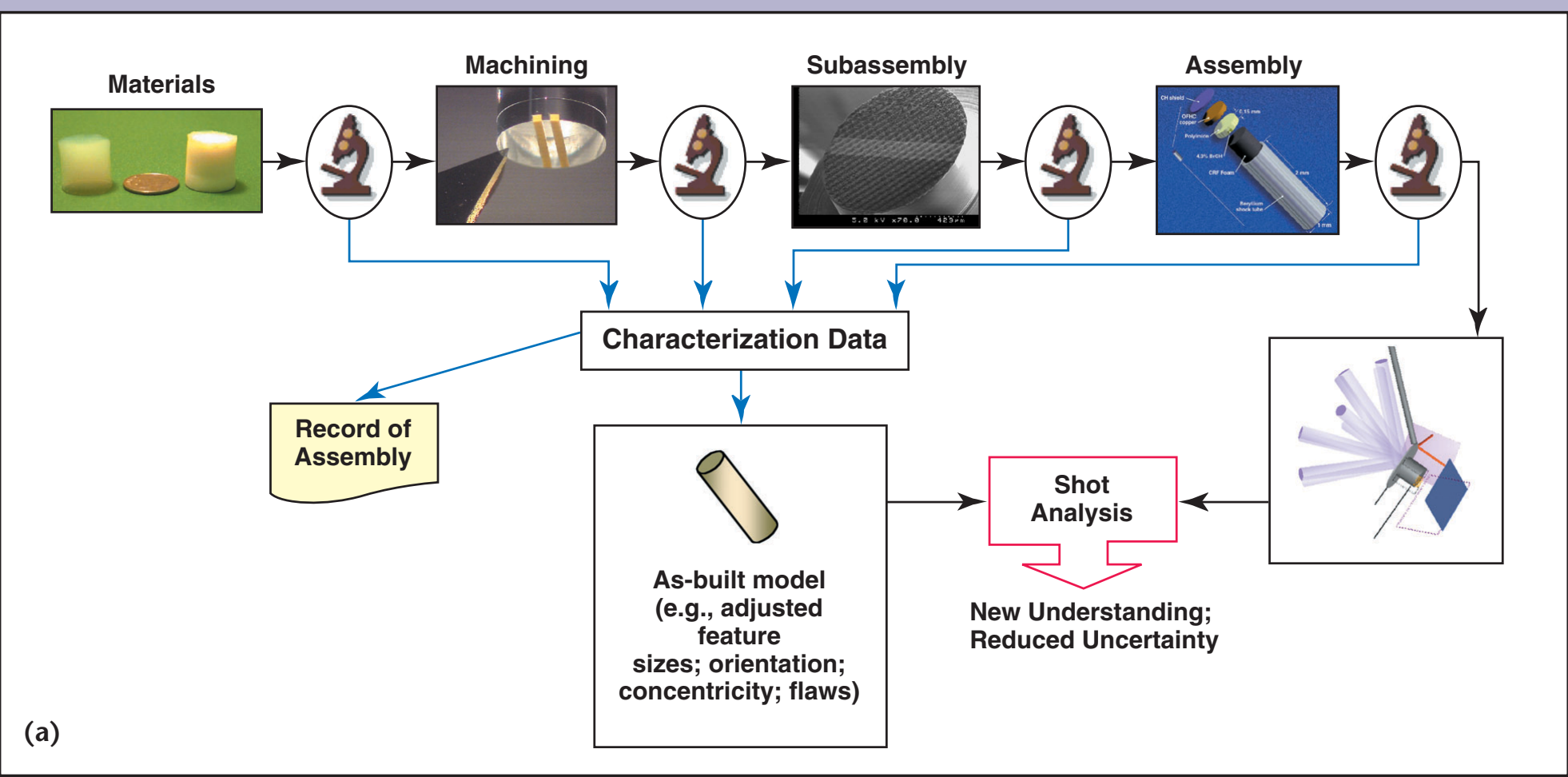

In addition to the ER projects,

Engineering and the Chemistry \& Materials Science Directorate also proposed a Strategic Initiative on the characterization of future target assemblies. As critical as developing fabrication and assembly techniques, the characterization is essential in providing the target designer with "as-built" measurements of component placement, gaps, concentricity, deformations, and so forth that are critical to performing an accurate target simulation on a computer. Four techniques were included in the proposal: an x-ray microscope, proton radiography, nuclear magnetic resonance (NMR) on foams, and high-frequency acoustics. Each of these techniques would yield a specific piece of information on the target assembly.

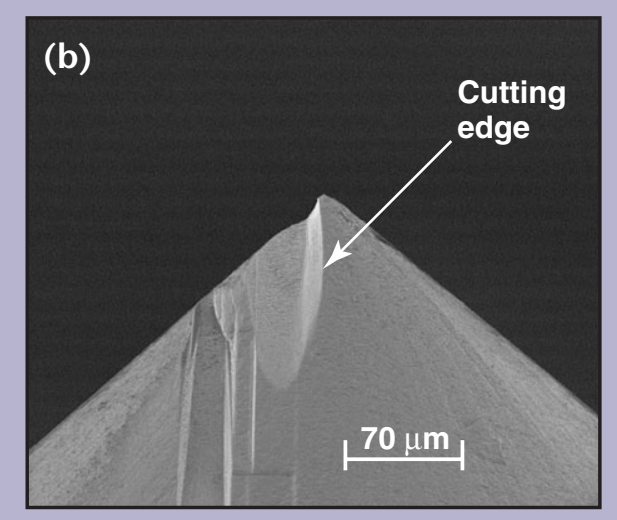

Left page, inset (a): 100-Hz commercial fast tool servo owned by LLNL.

Left page, inset (b): A geometric model of the base of an $x$-ray microscope that will be used for characterizing target assemblies. The instrument should provide submicrometer resolution of an object over a quarter-millimeter field of view.

Right page, inset (a): Characterization must be an integral part of target fabrication. The nondestructive methods proposed in our Strategic Initiative will provide data to improve simulations using as-built target models. They will also provide a better understanding of the experimental results. Both will contribute to a new understanding of high-energy-density physics and reduce uncertainties.

Right page, inset (b): We are investigating the use of ultra-short pulse lasers to produce extremely precise tools that will in turn be used in producing submicrometer features on laser targets. Early attempts yielded this cutting edge in a diamond tip. 


\section{Future Priorities}

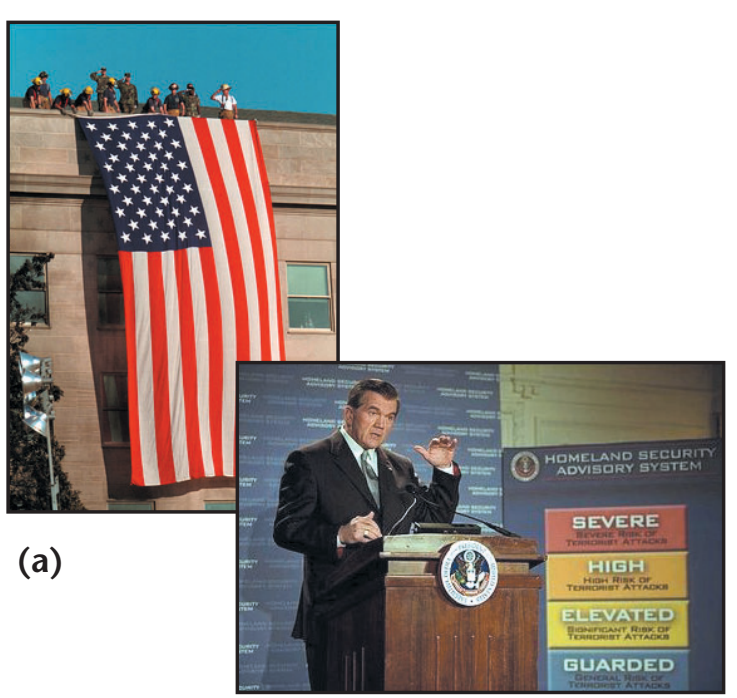

Engineering is highly regarded as the backbone of the Laboratory, the organization that provides expertise when programs require it, reassigns Engineering personnel when programs are completed, and develops critical skills to meet future priorities. After a decrease in Engineering's workforce from 3000 to 2000 employees over 12 years, the last few years have seen a significant increase in hiring: almost 290 employees hired in FY02, with 40 percent new graduates.

As the Laboratory's national security mission evolves to respond to new national priorities such as counterterrorism, Engineering's priorities must keep pace. It is vital to maintain a robust workforce that can meet the demanding timeline of the National Ignition Facility commissioning and operation, fulfill the engineering requirements of defense and national security programs, and propel the frontiers of new engineering science and technologies. Therefore, our top priorities for 2003 are:

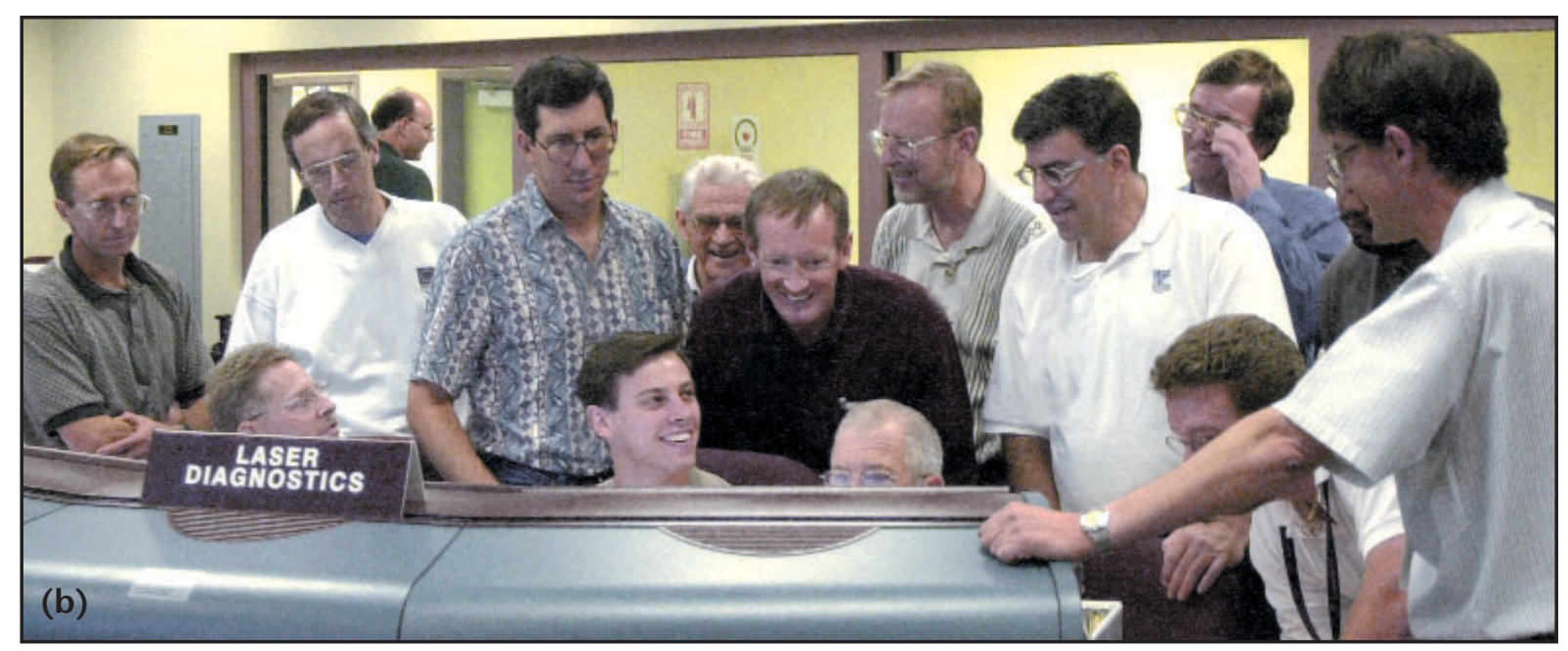

- Achieve engineering milestones for NIF Early Light (NEL) and subsequent commissioning and experimental activities.

- Fulfill commitments to the W80 program and lead in Engineering-based stockpile stewardship.

- Organize to support the new federal Department of Homeland Security.

- Continue to set the Laboratory standard for people management in such areas as performance management and leadership development.

- Invest in people, with emphasis on recent hires and the Engineering work environment.

- Provide opportunities for career growth of Engineering personnel so that they are prepared to take on a variety of programmatic and institutional leadership roles.

- Implement additional Survey Action Team (SAT) recommendations from the employee survey and serve as the pilot organization where appropriate. Continue the restarted machinist apprenticeship program.

- Continue Engineering facility and infrastructure revitalization, and develop a longer-term facilities and equipment strategic plan. 


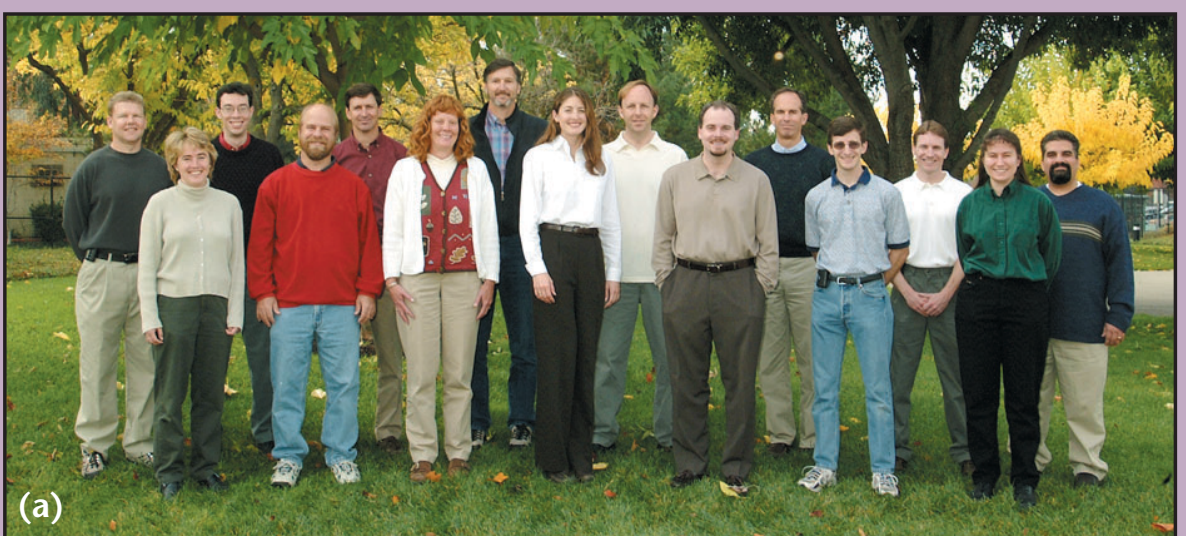

- Develop a science and technology investment strategy that aligns with the overall Laboratory plan.

- Maintain initiatives related to safety and security. Ensure proper focus and attention on all matters pertaining to environment, safety, and health and the new Integrated Safeguards and Security Management program.

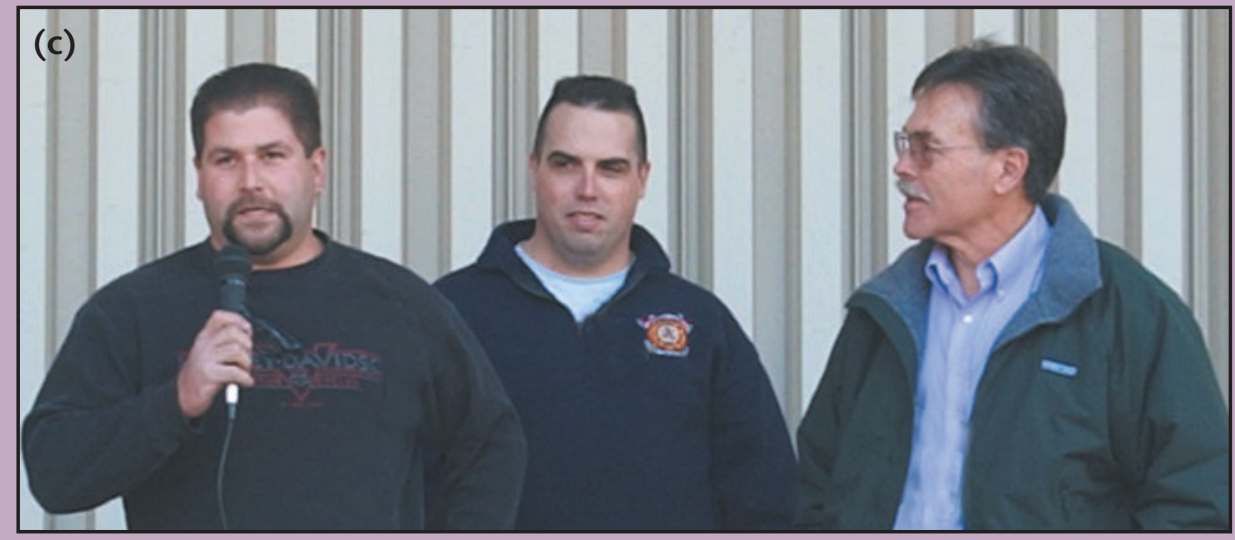

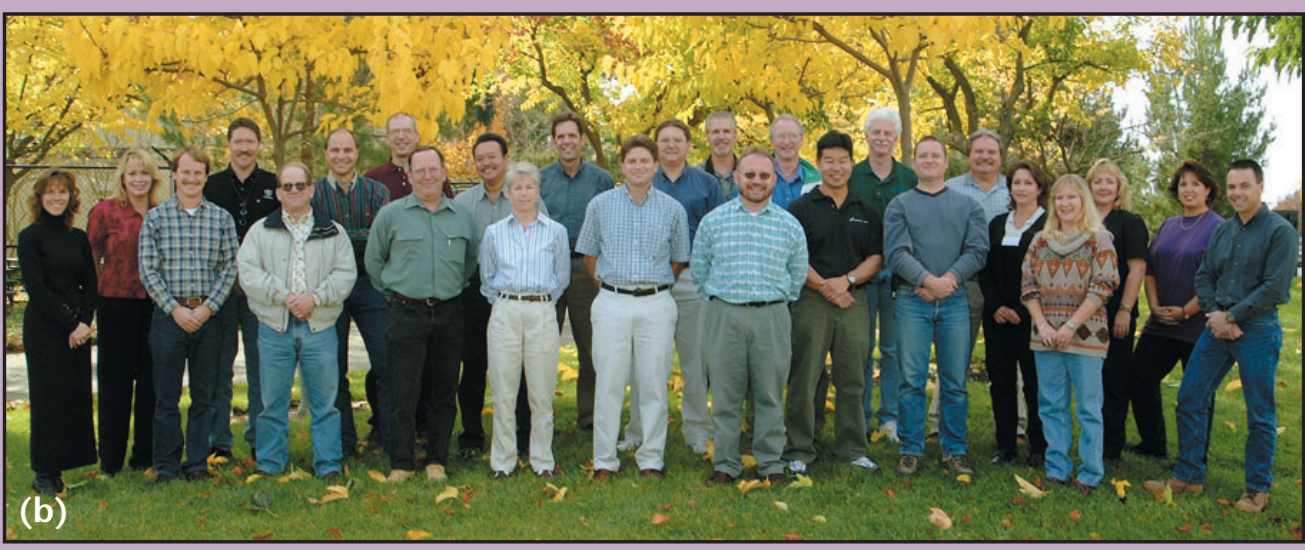

Left page, inset (a): In the wake of the September 11, 2001 tragedy, President Bush and Congress acted to create the Department of Homeland Security. Engineering and the rest of the Laboratory will be at the forefront, supporting the new department with science and technology to help keep our nation secure.

Left page, inset (b): A series of highly successful NIF test shots at the end of 2002 has paved the way for NIF Early Light, or NEL, in spring 2003: the transport of four ultraviolet beams of laser light into the target chamber.

Right page, insets (a) and (b): Engineering's Leadership Development Program is designed to build a pool of trained younger employees ready to take on leadership tasks, and also provides advanced training for current leaders within Engineering. The Technical Administrative Leadership Program provides similar training opportunities for Engineering employees in technical and administrative career paths. Recent participants in both programs are shown.

Right page, inset (c): Jason Carroll (left) and Paul Alexander (center) are the first two machinist apprentices hired under Engineering's revived apprentice program; on the right is program coordinator John Fry. Reinstituted in response to feedback received from the all-employee survey conducted in 2001 Engineering's apprentice program provides a hands-on way of transferring skills, knowledge, and ability to new people. 


\section{Honors, Awards, and Patents}

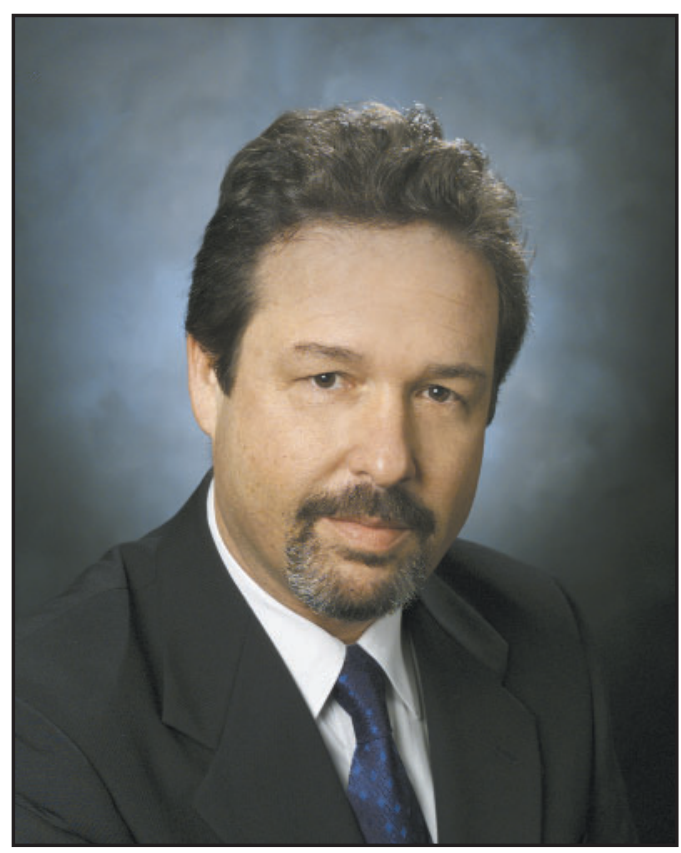

\section{R\&D 100 Awards}

Silicon Monolithic Microchannel (SiMM) Laser Diode Array

Joseph J. Satariano, Jacqueline J. Crawford, Barry L. Freitas, Gary E. Loomis, Terri L. Delima-Hergert,

Dave A. Van Lue, Kurt P. Cutter, Everett J. Utterback, Catherine E. Reinhardt

Solid-State Heat-Capacity Laser (SSHCL)

Balbir S. Bhachu, William J. Manning, Scott N. Fochs, James D. Wintemute, Steven B. Sutton, Georg F. Albrecht, Mark D. Rotter

Production-Scale Thin-Film Coating Tool

James A. Folta, Mark A. Schmidt, R. Frederick Grabner

STIM-2002 TENS Pain Management Device

Theodore T. Saito

\section{Professional Honors and Offices}

American Glovebox Society

Board of Directors: Larry J. Walkley

American Nuclear Society

Chairman, Northern California Section: Mark A. Mitchell

American Society of Mechanical Engineers

Principal Editor, Transportation, Disposal, and Storage of Radioactive Materials and Technical Sessions Developer (ASME Pressure Vessels and Piping Conference, Atlanta, GA): Ronald S. Hafner; Contributing Editor, Seismic Engineering and Technical Sessions Chairman (ASME Pressure Vessels and Piping Conference, Atlanta, GA): Stephen C. Lu
California Governor's Task Force for the Safe Delivery of Fuels

Chairman, Subcommittee for Field Testing:

David B. McCallen

The Institute of Electrical and Electronics Engineers Treasurer, 2004 Nuclear Science Symposium and Medical Imaging Conference: Anthony D. Lavietes; Assistant Editor, IEEE Nuclear Science Symposium: Brad W. Sleaford; Chairman, Laser Pulsed Power Session of Pulsed Power Plasma Science Conference: Douglas W. Larson; Co-Chairman, Technical Program, Pulsed Power Plasma Science Conference: Mark A. Newton

Memorial Institute for the Prevention of Terrorism Panel Member, Panel to Review Overall Research Program: Raymond P. Mariella, Jr.

National Academies/National Research Council Panel Member, Panel on Materials and Manufacturing Processes for Advanced Sensors: Raymond P. Mariella, Jr.

\section{Project Management Institute}

Certified Project Management Professional: Karl H. Krause

SPIE-The International Society for Optical Engineering Member, Editorial Board and Program Committee, Subsurface Sensing Technologies and Applications Section: Rexford M. Morey; Photonics West Special Session on LLNL:

Steven W. Bond

University of the Pacific, Stockton

Steering Committee for Biomedical Engineering: Kevin C. O'Brien 


\section{Honors, Awards, and Patents}

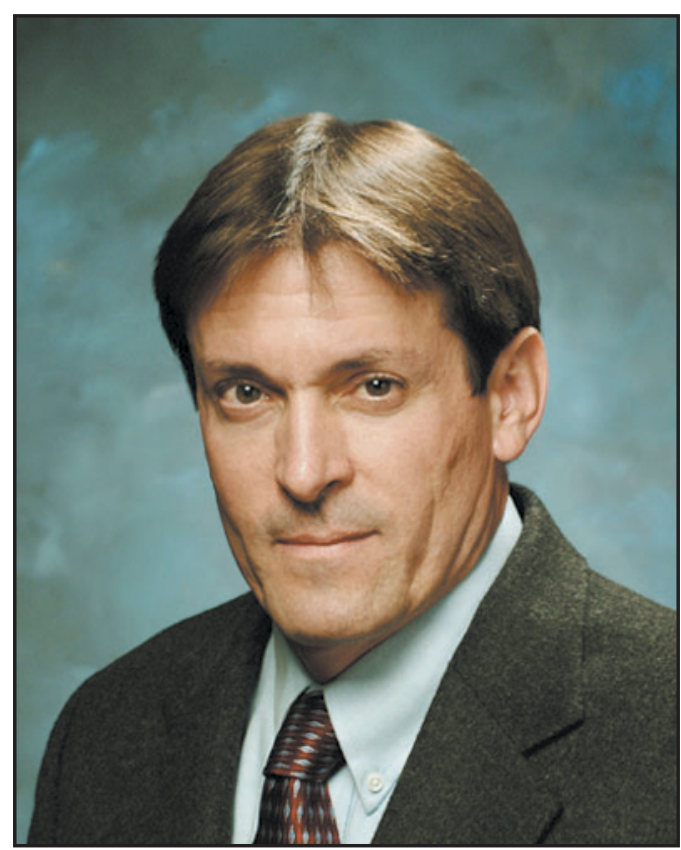

\section{Patents}

\section{1}

Adhesion Layer for Etching of Tracks in Nuclear Trackable Materials Jeffrey D. Morse, Robert J. Contolini

\section{Amorphous-Diamond} Electron Emitter

Steven Falabella

Apparatus for Loading Shape Memory Gripper Mechanisms Abraham P. Lee, William J. Benett, Daniel L. Schumann, Peter A. Krulevitch, Joseph P. Fitch

\section{Bi-Stable Optical Element} Actuator Device

Fred R. Holdener

Enhanced Modified Faraday Cup for Determination of Power Density Distribution of Electron Beams John W. Elmer, Alan T. Teruya

Fabrication of Precision High-Quality Facets on Molecular Beam Epitaxy Material

Holly E. Petersen, William D. Goward, Sol P. Dijaili
Generation of Low Work Function, Stable Compound Thin Films by Laser Ablation

Long N. Dinh, William McLean II, Mehdi Balooch, Edward J. Fehring, Jr., Marcus A. Schildbach

\section{- $\because . .$. Hand-Held Multiple System Gas Chromatograph \\ Conrad M. Yu}

High Efficiency Replicated X-Ray Optics and Fabrication Method

Troy W. Barbee, Jr., Stephen M. Lane, Donald E. Hoffman

High Sensitivity Charge Amplifier for Ion Beam Uniformity Monitor

Gary W. Johnson

High Voltage Photovoltaic Power Converter Ronald E. Haigh, Steve Wojtczuk, Gerard F. Jacobson, Karla G. Hagans

Highly Damped Kinematic Coupling for Precision Instruments

Layton C. Hale, Steven A. Jensen

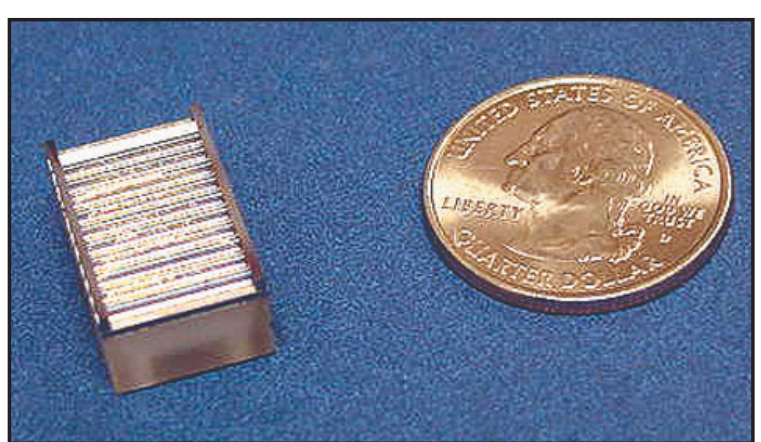

Method for Vacuum Fusion Bonding Harold D. Ackler, Stefan P. Swierkowski, Lisa A. Tarte, Randall K. Hicks

Microfabricated Instrument for Tissue Biopsy and Analysis Peter A. Krulevitch, Abraham P. Lee, M. Allen Northrup,

William J. Benett 


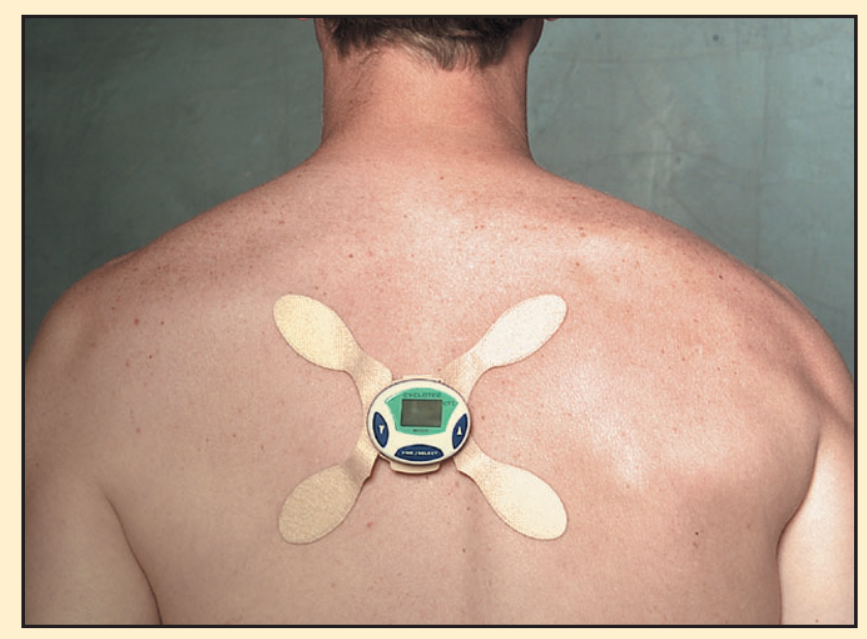

Microfluidic Interconnects

William J. Benett, Peter A. Krulevitch

Micromachined Low Frequency Rocking Accelerometer with Capacitive Pickoff

Abraham P. Lee, Jonathan N. Simon, Charles F.

McConaghy

Modified Electrokinetic Sample Injection Method in Chromatography and Electrophoresis Analysis

J. Courtney Davidson, Joseph W. Balch

\section{Monolithic Laser Diode Array with One Metallized} Sidewall

Barry L. Freitas, Jay A. Skidmore, John P. Wooldridge,

Mark A. Emanuel, Stephen A. Payne

NOx Reduction System Utilizing Pulsed Hydrocarbon Injection

Raymond M. Brusasco, Bernardino M. Penetrante, George E. Vogtlin, Bernard T. Merritt

Paper Area Density Measurement from Forward Transmitted Scattered Light

Jackson C. Koo
Pedestal Substrate for Coated Optics

Layton C. Hale, Terry N. Malsbury, Steven R. Patterson

Process for Fabricating Composite Material Having

High Thermal Conductivity

Nicholas J. Colella, Howard L. Davidson, John A. Kerns,

Daniel M. Makowiecki

Process for Manufacturing Hollow Fused-Silica

Insulator Cylinder

Stephen E. Sampayan, Derek E. Decker, David M. Sanders

System and Method for Chromatography and Electrophoresis Using Circular Optical Scanning Joseph W. Balch, Laurence R. Brewer, James C.

Davidson, Joseph R. Kimbrough

\section{System and Method for Optically Locating}

Microchannel Positions

Laurence R. Brewer, Joseph Kimbrough, Joseph Balch,

J. Courtney Davidson

Two Position Optical Element Actuator Device Fred R. Holdener

Use of a Hard Mask for Formation of Gate and Dielectric Via Nanofilament Field-Emission Devices Jeffrey D. Morse, Robert J. Contolini

Vacuum Fusion Bonded Glass Plates Having Microstructures Thereon

Stephan P. Swierkowski, James C. Davidson, Joseph W. Balch

Vacuum-Surface Flashover Switch with Cantilever Conductors

Stephen E. Sampayan, Hugh C. Kirbie
Left page: Dave McCallen was named Chairman of the Subcommittee for Field Testing, California Governor's Task Force for the Safe Delivery of Fuels.

Left page, insets: Engineering personnel shared in an R\&D 100 Award for the Silicon Monolithic Microchannel (SiMM) Laser Diode Array. A 41-kilowatt laser diode array constructed from 28 individual packages of SiMMs is shown. Below that, a single SiMM package is pictured next to a quarter for scale.

Right page: Participation in the development of the STIM-2002 TENS pain management device earned Engineering recognition in another $R \& D 100$ Award-winning effort. 


\section{Honors, Awards, and Patents}

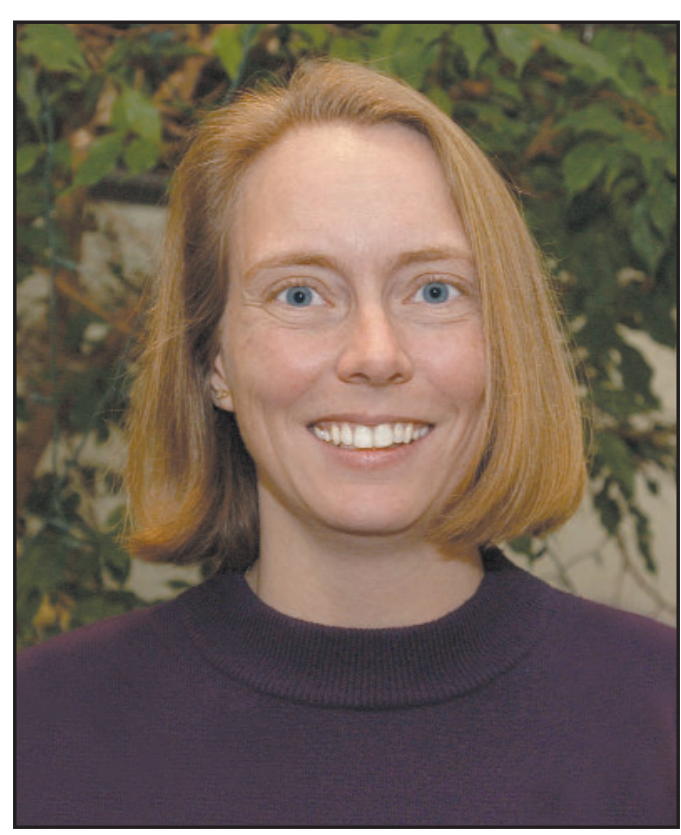

\section{2}

Alternating-Polarity Operation for Complete Regeneration of Electrochemical Deionization System Tri D. Tran, David J. Lenz

Apparatus and Method for Collection and Concentration of Respirable Particles into a Small Fluid Volume

Jonathan N. Simon, Steve B. Brown

Apparatus for Improving Performance of Electrical Insulating Structures

Michael J. Wilson, David A. Goerz

Charge Amplifier with Bias Compensation

Gary W. Johnson

Coatings on Reflective Mask Substrates

William Man-Wai Tong, John S. Taylor, Scott D. Hector, Pawitter J. S. Mangat, Alan R. Stivers, Patrick G. Kofron, Matthew A. Thompson

Compact Multiwavelength Transmitter Module for Multimode Fiber Optic Ribbon Cable

Robert J. Deri, Michael D. Pocha, Michael C. Larson, Henry E. Garrett

High Average Power Scaleable Thin-Disk Laser Raymond J. Beach, Eric C. Honea, Camille Bibeau, Stephen A. Payne, Howard Powell, William F. Krupke, Steven B. Sutton

High-Speed Pulse-Shape Generator, Pulse Multiplexer Scott C. Burkhart
Low Cost Impulse Compatible Wideband Antenna Erwin T. Rosenbury, Gerald K. Burke, Scott D. Nelson, Robert D. Stever, George K. Governo,

Donald J. Mullenhoff

Metals Removal from Spent Salts

Peter C. Hsu, Erica H. von Holtz, David L. Hipple, Leslie J. Summers, William A. Brummond,

Martyn G. Adamson

Method for Improving Performance of Highly Stressed Electrical Insulating Structure

Michael J. Wilson, David A. Goerz

Microfluidic DNA Sample Preparation Method and Device

Peter A. Krulevitch, Robin R. Miles, Xiao-Bo Wang, Raymond P. Mariella, Jr., Peter R. C. Gascoyne, Joseph W. Balch

\section{Miniature X-Ray Source}

James E. Trebes, Gary F. Stone, Perry M. Bell, Ronald B. Robinson, Victor I. Chornenky

Optical Coherence Tomography Guided Dental Drill Luiz B. Da Silva, Bill W. Colston, Jr., Dale L. James

Opto-Acoustic Recanilization Delivery System Steven R. Visuri, Luiz B. Da Silva, Peter M. Celliers, Richard A. London, William Benett, Kathryn Broughton, Victor Esch

Plasma-Assisted Catalytic Storage Reduction System Bernardino M. Penetrante, George E. Vogtlin, Bernard T. Merritt, Raymond M. Brusasco 

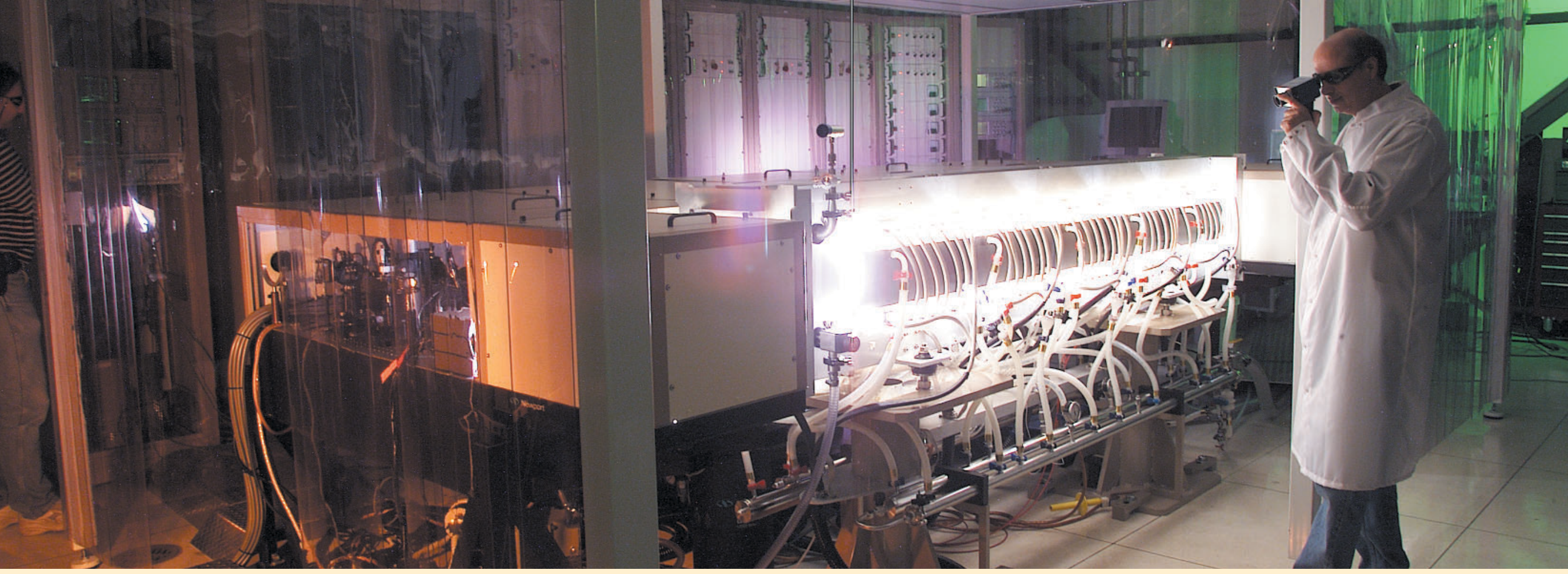

Portable Gas Chromatograph Mass Spectrometer for On-Site Chemical Analyses

Jeffrey S. Haas, John F. Bushman, Douglas E. Howard, James L. Wong, Joel D. Eckels

Printed Circuit Board for a CCD Camera Head Alan D. Conder

\section{Rotational Rate Sensor}

Steven L. Hunter

Self Adjusting Inclinometer

Steven L. Hunter

\section{Solar Cell Module Lamination Process}

Paul G. Carey, Jesse B. Thompson, Randy C. Aceves

Sputtering Process and Apparatus for Coating Powders Daniel M. Makowiecki, John A. Kerns, Craig S. Alford, Mark A. McKernan
System and Method for $\mathbf{1 0 0} \%$ Moisture and Basis Weight Measurement of Moving Paper

Jose E. Hernandez, Jackson C. Koo

\section{System and Method for Characterizing Voiced} Excitations of Speech and Acoustic Signals, Removing Acoustic Noise from Speech, and Synthesizing Speech Greg C. Burnett, John F. Holzrichter, Lawrence C. Ng

Thermally Robust Semiconductor Optical Amplifiers and Laser Diodes

Sol P. Dijaili, Frank G. Patterson, Jeffrey D. Walker, Robert J. Deri, Holly Petersen, William Goward

\section{Tiltmeter Leveling Mechanism}

Steven L. Hunter, Carl O. Boro, Alvis Farris
Left page: Engineer Abbie Warrick was honored in 2001 with International SEMATECH's

Corporate Excellence Award for her part in the development and fabrication of programmed defect reference wafers for the Intentional Defect Arrays project.

Right page: Balbir Bhachu, a laser technician, monitors the performance of the solid-state heatcapacity laser (SSHCL). Engineers were part of the team that developed the SSHCL, which garnered yet another R\&D 100 Award in 2002. 


\section{Engineering Statistics}

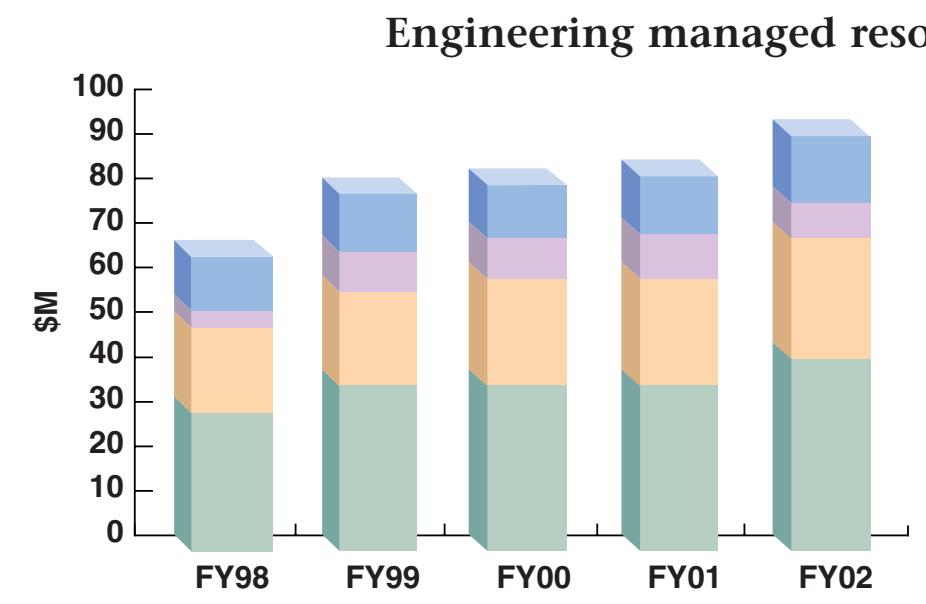

Engineering staffing profile (as of 12/31/01)

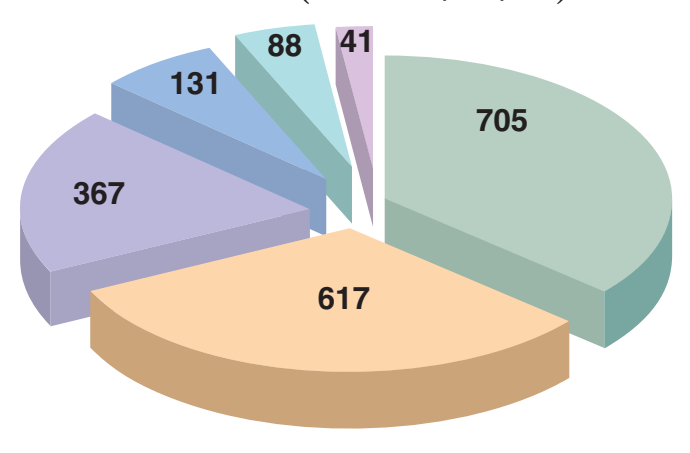

Engineer

Technician/Drafter

Supervisor/Associate

Machinist

Non-exempt Admin.

Exempt Admin.

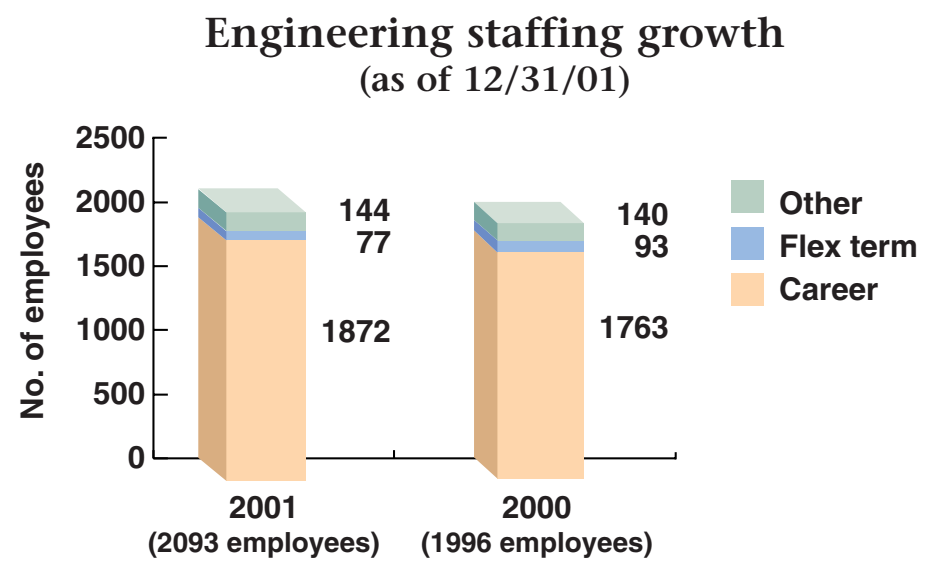

Engineering staffing profile (as of 12/31/02)

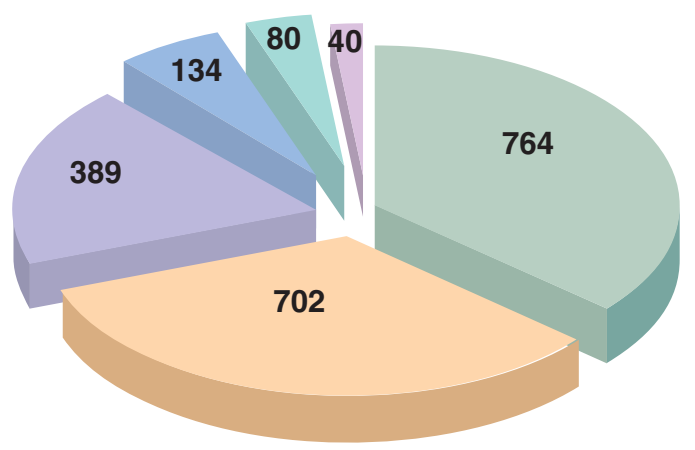

Engineer

Technician/Drafter

Supervisor/Associate

Machinist

Non-exempt Admin.

Exempt Admin.

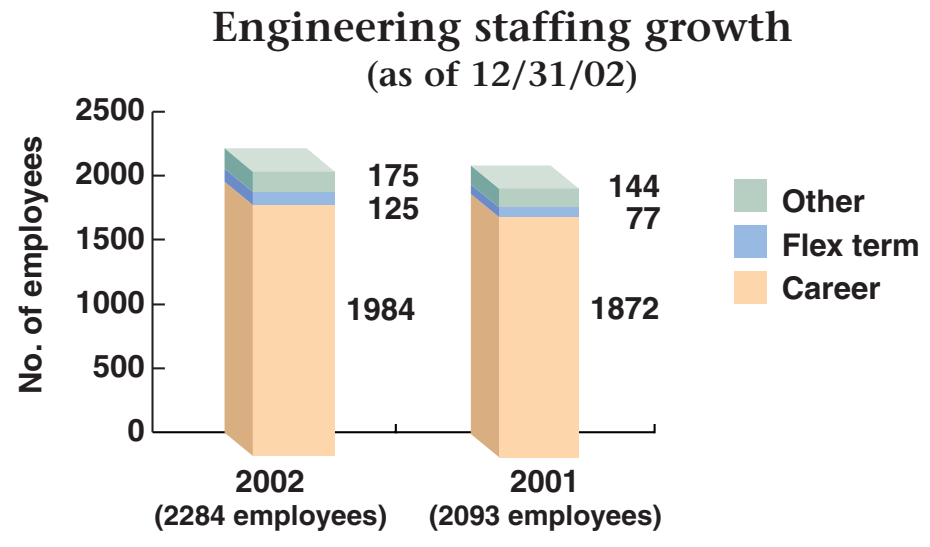




\section{Laboratory Statistics}

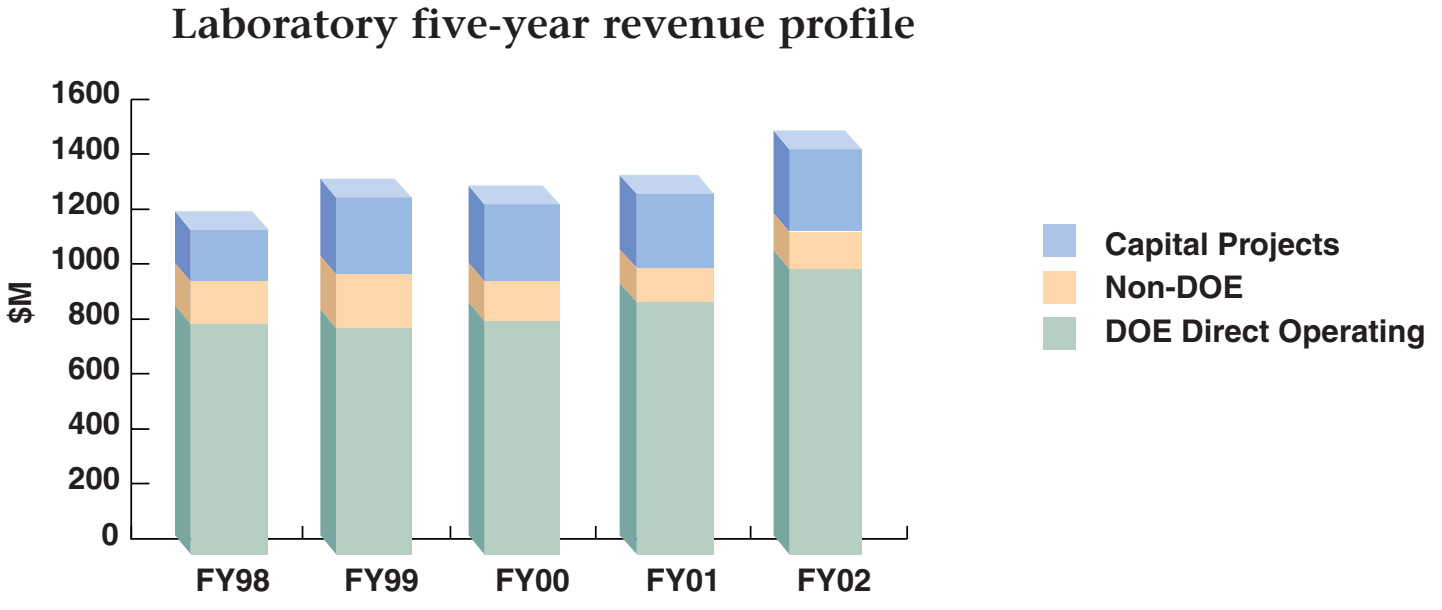

Laboratory degree distribution

(as of 12/31/02)
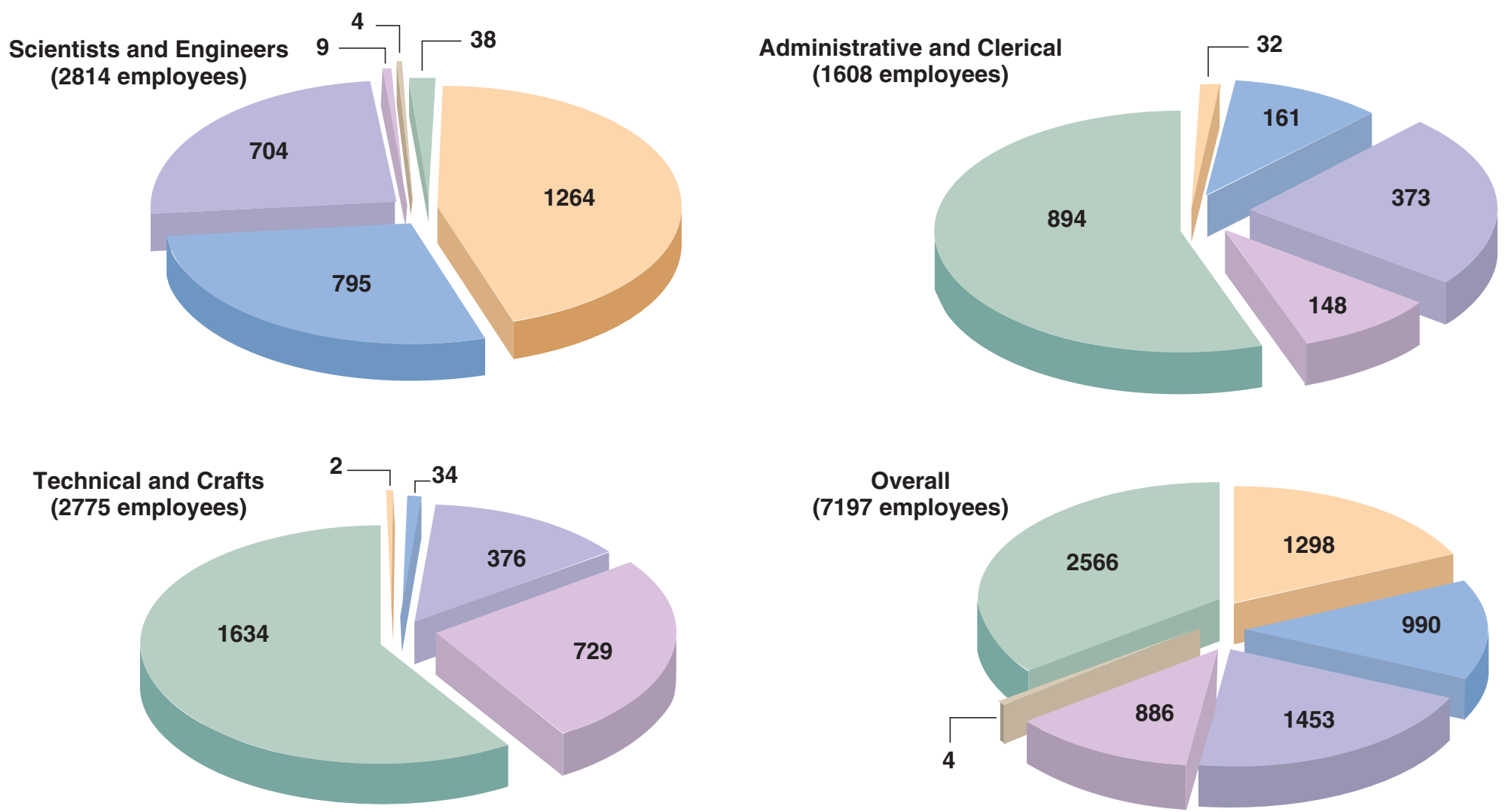

Overall

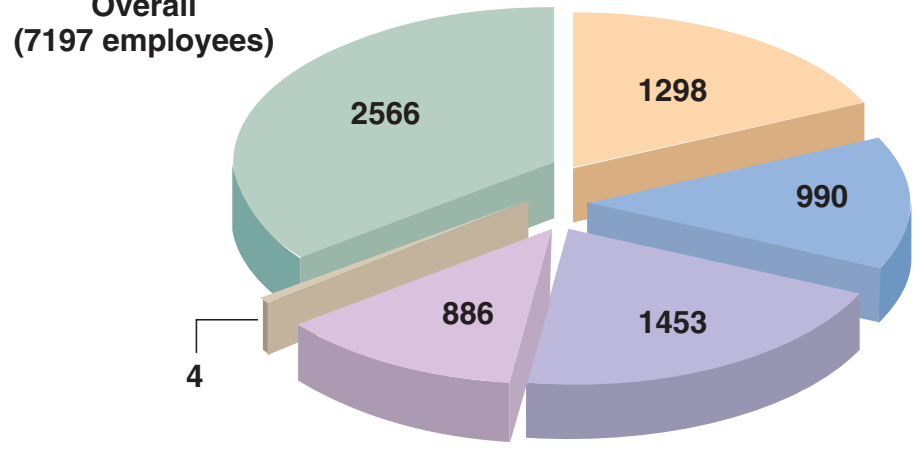

AA 


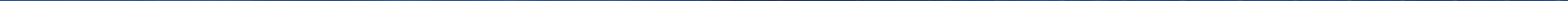

